\title{
Bacterial cellulose-lactoferrin as an antimicrobial edible packaging
}

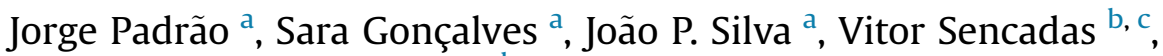 \\ Senentxu Lanceros-Méndez ${ }^{b}$, Ana C. Pinheiro a , António A. Vicente ${ }^{a}$, Ligia R. Rodrigues a , \\ Fernando Dourado ${ }^{\text {a, * }}$
}

a Centre of Biological Engineering, University of Minho, Campus de Gualtar, 4710-057, Braga, Portugal

${ }^{\mathrm{b}}$ Centre/Department of Physics, University of Minho, Campus de Gualtar, 4710-057, Braga, Portugal

' School of Mechanical, Materials and Mechatronics Engineering, University of Wollongong, Wollongong, NSW, 2522, Australia

\section{A R T I C L E I N F O}

\section{Article history:}

Received 30 April 2015

Received in revised form

19 January 2016

Accepted 16 February 2016

Available online 24 February 2016

\section{Keywords:}

Bacterial cellulose

Bovine lactoferrin

Active packaging

Antimicrobial

Cytotoxicity

Gastrointestinal tract model

\begin{abstract}
A B S T R A C T
Bacterial cellulose (BC) films from two distinct sources (obtained by static culture with Gluconacetobacter xylinus ATCC 53582 (BC1) and from a commercial source (BC2)) were modified by bovine lactoferrin (bLF) adsorption. The functionalized films $(B C+b L F)$ were assessed as edible antimicrobial packaging, for use in direct contact with highly perishable foods, specifically fresh sausage as a model of meat products. $\mathrm{BC}+$ bLF films and sausage casings were characterized regarding their water vapour permeability (WVP), mechanical properties, and bactericidal efficiency against two food pathogens, Escherichia coli and Staphylococcus aureus. Considering their edibility, an in vitro gastrointestinal tract model was used to study the changes occurring in the $\mathrm{BC}$ films during passage through the gastrointestinal tract. Moreover, the cytotoxicity of the BC films against 3T3 mouse embryo fibroblasts was evaluated.

BC1 and BC2 showed equivalent density, WVP and maximum tensile strength. The percentage of bactericidal efficiency of BC1 and BC2 with adsorbed bLF (BC1 + bLF and BC2 + bLF, respectively) in the standalone films and in inoculated fresh sausages, was similar against $E$. coli (mean reduction $69 \%$ in the films per se versus $94 \%$ in the sausages) and S. aureus (mean reduction $97 \%$ in the films per se versus $36 \%$ in the case sausages). Moreover, the BC1 + bLF and $\mathrm{BC} 2+$ bLF films significantly hindered the specific growth rate of both bacteria. Finally, no relevant cytotoxicity against 3T3 fibroblasts was found for the films before and after the simulated digestion. BC films with adsorbed bLF may constitute an approach in the development of bio-based edible antimicrobial packaging systems.
\end{abstract}

(C) 2016 Elsevier Ltd. All rights reserved.

\section{Introduction}

Currently, food is much more than an item to insure nourishment. Food may be an important ambassador of a region, a country, a continent or even a culture. Therefore, the maintenance of the food organoleptic traits, like the flavour, texture, smell, quality assurance and food safety are crucial for the food industry. Consumer standards towards food freshness and safety have also increased exponentially over the last decades. Intensive research on food packaging is being developed to supply household tables with fresh, safe, minimal processed, easy to prepare products (Coma, 2008; Pereira de Abreu, Cruz, \& Paseiro Losada, 2011). Moreover, the implementation of renewable and biodegradable materials

\footnotetext{
* Corresponding author.

E-mail address: fdourado@deb.uminho.pt (F. Dourado).
}

must be adopted by the food industry in order to meet environmental standards (Cutter, 2006). Realini and Marcos (Realini \& Marcos, 2014) reviewed the different categories of active and intelligent packaging systems, listing also available commercial applications, the latest packaging research trends and innovations. Antimicrobial packaging, as a form of active packaging, aims at preventing foodborne illness by eradicating or inhibiting the existing or contaminating food microflora, thus increasing the product safety and promoting the extension of its shelf-life (Pereira de Abreu et al., 2011; Quintavalla \& Vicini, 2002). Irkin and Esmer (Irkin \& Esmer, 2015) reviewed the most important knowledge on the application of natural antimicrobial packaging with model food systems and their antimicrobial effects on food products.

Natural polymers exhibit several advantages as coatings and films such as edibility, biodegradability, biocompatibility and barrier properties (Pérez-Pérez, Regalado-González, BarbosaRodríguez, Rodríguez-Rodríguez, \& Villaseñor-Ortega, 2006; 
Siracusa, Rocculi, Romani, \& Rosa, 2008). Nanostructured bio-based materials are further endowed with higher surface area-to-volume ratio, as compared to their micro-sized counterparts (Azeredo, 2013; Duncan, 2011). Bacterial cellulose (BC) is an outstanding polymer extruded by Gluconacetobacter xylinus to yield a 3D nanofibrillar pure cellulosic network. BC exhibits high tensile strength, in situ moldability, water holding capacity, biocompatibility and biodegradability. These unique properties allowed exploring its potential mostly in the biomedical field, where temporary skin substitutes and artificial blood vessels appear as patented products. In Asian countries, as obtained by "traditional" fermentation methods, BC is produced and sold as "nata de coco", a low-calorie sweetened dessert and high-fiber food (Andrade, Pertile, Dourado, \& Gama, 2010; Shi, Zhang, Phillips, \& Yang, 2014). The use of BC as an active and/or intelligent food packaging is virtually unexploited. Nguyen et al. (Nguyen, Gidley, \& Dykes, 2008) published a proof-of-concept study on the use of BC films containing adsorbed nisin, to control Listeria monocytogenes and other bacteria, on the surface of vacuum-packaged frankfurters, as models for higher value meat products. Zhu et al. (Zhu et al., 2010) showed that $\varepsilon$-polylysine ( $\varepsilon$-PL) embedded onto BC, had no significant loss of antimicrobial activity after autoclaving at $121{ }^{\circ} \mathrm{C}$ for $30 \mathrm{~min}$. Also, sausages packaged with a BC $+\varepsilon-\mathrm{PL}$ composite showed a longer shelf-life than controls (without $\varepsilon-P L$ ). Additionally, Almeida et al. (Almeida, Prestes, Woiciechowski, \& Wosiacki, 2011) evaluated the potential of BC for the conservation of minimally processed fruits. Furthermore, Maneesri et al. (Maneesri, Masniyom, \& Pongpiriyadacha, 2012) studied the use of BC films containing Sarapee (Mammea siamensis) flower extract, against Salmonella typhimurium. To further potentiate the antibacterial activity of BC, $\varepsilon$-PL was cross-linked onto the surface of BC nanofibers, using procyanidins (Gao et al., 2014). Composites from $\mathrm{BC}+\varepsilon-\mathrm{PL}$ exhibited enhanced antibacterial activity against both Escherichia coli (Gram-negative bacteria) and Staphylococcus aureus (Gram-positive bacteria).

The existing literature on the use of $\mathrm{BC}$ as an active food packaging has been confined to demonstrating its in vitro antimicrobial effect towards some strains of pathogens. This work describes the surface functionalization of $\mathrm{BC}$ from distinct sources with bovine lactoferrin (bLF) and the assessment of its potential as an edible antimicrobial film, for use in direct contact with highly perishable foods, specifically meat products. The properties of BC (e.g. mechanical, porosity, crystallinity, fibre length and diameter) are known to vary according to the type of strain, composition of the culture media (nutrients), fermentation conditions (static versus agitated culture) and post-processing (purification) (Sani \& Dahman, 2010; Tang, Jia, Jia, \& Yang, 2009). Two distinct BC sources (as obtained by static culture with G. xylinus ATCC 53582 and from a commercial source) were thus functionalized with bLF, to evaluate their antimicrobial properties against E. coli and S. aureus, which represent two major microbial contaminants of meat food. Fresh sausage from a local butcher shop was used in the antimicrobial tests. BC + bLF films and the sausage casings, composed of pig small intestine, were characterized regarding their water vapour permeability (WVP), mechanical properties and bactericidal efficiency. BC films were herein tested, for the first time with BC, using an in vitro gastrointestinal tract model, to simulate the digestion of substrates. Finally, the cytotoxicity of the edible BC films against 3T3 mouse embryo fibroblasts was evaluated.

BLF is a glycoprotein with approximately $80 \mathrm{kDa}$ that has been found to possess a wide range of activities, such as immunoregulatory, anti-cancer and antimicrobial. It is considered a safe ingredient. Industrial scale production ranges between 80 and 100 tonnes a year (EFSA, 2012; Wakabayashi, Yamauchi, \& Takase, 2006). Moreover, bLF antimicrobial action against foodborne pathogens such as S. aureus (Bhimani, Vendrov, \& Furmanski, 1999), E. coli (Håkansson et al., 2001; Håversen et al., 2000) and Clostridium spp (Teraguchi et al., 1995) have been reported.

\section{Materials and methods}

BC from two different origins were used in this study: i) "BC1", produced in the laboratory by static culture of G. xylinus ATCC 53582 , ii) "BC2", purchased commercial grade 2 raw nata de coco, from HTK Food CO. Ltd. (Vietnam). bLF protein was purchased from DMV International (USA) with a composition of $96 \%$ dry weigh percentage of protein, approximately $120 \mathrm{ppm}$ of iron, $0.5 \%(\mathrm{w} / \mathrm{w})$ of ash and $3.5 \%(\mathrm{w} / \mathrm{w})$ of moisture. The BC films with adsorbed bLF were named $\mathrm{BC} 1+\mathrm{bLF}$ and $\mathrm{BC} 2+\mathrm{bLF}$, for the laboratory produced and the commercially acquired $\mathrm{BC}$, respectively. Fresh sausages, bought at a local butcher shop (and produced in the northwest region of Portugal), were used as a model food product to evaluate the antimicrobial activity of the films. Its label information was the following: "pig's meat and fat, pepper, salt, spices, soy protein, emulsifier (E450 and E451), antioxidant (E316 and 331), colorant (E316) and stabilizer (E250), it contains soybean, milk and celery. Maintain between 0 and $5{ }^{\circ} \mathrm{C}$. The casing, composed of pig small intestine, was used as control in the assessment of the water vapour permeability (WVP), mechanical properties, and in the bactericidal efficiency, as described below.

\subsection{Culture media}

G. xylinus (ATCC 53582) was maintained in Hestrin-Schramm culture medium (HS) (Hestrin \& Schramm, 1954) in solid state with $2 \%(\mathrm{w} / \mathrm{v}$ ) agar (Himedia). BC1 fermentation occurred in static culture conditions using $\mathrm{HS}$ with a flask volume ratio of $1 / 4$, at $25^{\circ} \mathrm{C}$ for at least four weeks. The reagents and quantities (w/v) used for HS medium preparation were $2 \%$ glucose (Sigma-Aldrich), $0.5 \%$ peptone (Sigma-Aldrich), 0.5\% yeast extract (Himedia), $0.34 \%$ $\mathrm{Na}_{2} \mathrm{HPO}_{4} \cdot 2 \mathrm{H}_{2} \mathrm{O}$ (Sigma-Aldrich), $0.15 \%$ citric acid (Pronolab). The final $\mathrm{pH}$ was adjusted to $5.5 \mathrm{using} \mathrm{HCl} \mathrm{18 \%} \mathrm{(v/v)} \mathrm{(Sigma-Aldrich).}$

Mueller-Hinton (MH) agar (Himedia) was used for E. coli and S. aureus maintenance and colony forming units (CFU) determination. These microorganisms were incubated overnight, prior to any experiment to produce the inoculum. The liquid culture media used for the antibacterial assays was Nutrient Broth (NB) (Himedia), and all liquid media pre-inoculum and experiments were carried out using a $1 / 5$ culture medium/flask volume ratio in an incubator at $37^{\circ} \mathrm{C}$, under shaking at $120 \mathrm{rpm}$ (Heidoph). HS (solid and liquid), $\mathrm{MH}$ agar and NB were autoclaved for $20 \mathrm{~min}$, at $120{ }^{\circ} \mathrm{C}$ and 1 bar (AJC 88) before use.

\subsection{Bacterial cellulose processing}

The same purification procedure was undertaken in both $\mathrm{BC} 1$ and $\mathrm{BC} 2$ membranes: once the $\mathrm{BC} 1$ production was terminated, or immediately after unpacking $\mathrm{BC} 2$, the membranes were autoclaved, in order to disrupt the G. xylinus cells in BC1, and to eliminate potential contaminants in BC2. After cooling, the membranes were rinsed with tap water and submerged into $4 \%(\mathrm{w} / \mathrm{v}) \mathrm{NaOH}$ (Fisher) for $24 \mathrm{~h}$ to remove any unwanted residues from the BC matrix. Afterwards, $\mathrm{BC}$ membranes were abundantly rinsed with distilled water until the $\mathrm{pH}$ equalled that of the distilled water. Finally, the never-dried BC membranes were cut into $1 \mathrm{~mm}$ thick slices, autoclaved in distilled water and stored in aseptic conditions until further use. 


\subsection{Adsorption of bLF onto $B C$}

Adsorption of bLF onto BC nanofibres was achieved under sterile conditions, by immersing never-dried BC films in phosphate buffer saline (PBS) ( $\mathrm{pH} 7.4$ ) (control samples) and in PBS with $10 \mathrm{mg} \mathrm{mL}^{-1}$ of bLF (BC + bLF samples), for $24 \mathrm{~h}$, with mild stirring at room temperature ( $\mathrm{RT}=25^{\circ} \mathrm{C}$ ), using a ratio of $4.5 \mathrm{mg}$ of $\mathrm{BC}$ per $\mathrm{mL}$ of solution. Afterwards, the films were vacuum dried at RT for $48 \mathrm{~h}$ and stored at in a desiccator aseptically, no longer than a week before use. PBS was autoclaved for $20 \mathrm{~min}$, at $120^{\circ} \mathrm{C}$ and 1 bar (AJC 88 ) before use. bLF solutions were prepared immediately before use in PBS and were filter-sterilized $(0.22 \mu \mathrm{m})$. PBS composition $(\mathrm{w} / \mathrm{v})$ was $0.8 \% \mathrm{NaCl}$ (Fisher), $0.02 \% \mathrm{KCl}$ (Fischer), $0.14 \% \mathrm{Na}_{2} \mathrm{HPO}_{4}$ (Sigma), $0.03 \% \mathrm{KH}_{2} \mathrm{PO}_{4}$ (Flücka).

Prussian blue staining and the adsorption-desorption studies described below, were performed using never-dried BC membranes. All the other assays were done using vacuum dried films.

\subsection{BC edible films physicochemical characterization}

\subsubsection{Prussian blue staining of $B C+b L F$ films}

$\mathrm{BC} 1$ and $\mathrm{BC} 2$ disks $(0.5 \mathrm{~mm}$ in diameter) were separately immersed into PBS or bLF solutions for $24 \mathrm{~h}$ at RT under mild stirring. Afterwards, the disks were collected and the excess of solution was removed using Whatman 1 filter paper. BC disks were immediately immersed in a Prussian blue solution for $30 \mathrm{~min}$ at RT. Prussian blue solution composition was $5 \%(\mathrm{w} / \mathrm{v})$ of $\mathrm{K}_{4} \mathrm{Fe}(\mathrm{CN})_{6}$ mixed in a proportion of $1 / 1$ with $5 \%(\mathrm{v} / \mathrm{v})$ of $\mathrm{HCl}$ (Buser, Schwarzenbach, Petter, \& Ludi, 1977; Goncalves et al., 2013). The disks were then rinsed with distilled water, transversely cut using plastic scissors and placed on a microscopy slide. Samples were analysed in a stereo microscope (Olympus).

$\left[\mathrm{Fe}(\mathrm{CN})_{6}\right]^{4-}$ reaction with $\mathrm{Fe}^{3+}$ (Equation (1)) originates an intense blue coloration (Tafesse, 2003; Verdaguer, Galvez, Grade, \& Desplanches, 2002).

$4 \mathrm{Fe}^{3+}+3\left[\mathrm{Fe}^{\mathrm{II}}(\mathrm{CN})_{6}\right]^{4-}+14 \mathrm{H}_{2} \mathrm{O} \rightarrow \mathrm{Fe}^{\mathrm{III}} 4\left[\mathrm{Fe}^{\mathrm{II}}(\mathrm{CN})_{6}\right]_{3} \cdot 14 \mathrm{H}_{2} \mathrm{O}$

\subsubsection{Ultraviolet-visible spectroscopy and Fourier transform infrared spectroscopy with attenuated total reflectance}

Ultraviolet-visible (UV) spectroscopy allows the identification of the characteristic absorbance profiles of proteins (Belitz \& Grosch, 1999). Absorbance profiles were registered within the wavelengths ranging from $200 \mathrm{~nm}$ to $700 \mathrm{~nm}$ (Jasco).

$\mathrm{BC}$ and $\mathrm{BC}+$ bLF films were analysed by Fourier Transform Infrared Spectroscopy with Attenuated Total Reflectance (FTIR-ATR, Alpha-FT-IR spectrometer (Bruker)). The spectra were collected with a resolution of $4 \mathrm{~cm}^{-1}$ after 32 scans that ranged from 4000 to $400 \mathrm{~cm}^{-1}$.

\subsection{3. bLF adsorption-desorption profile onto and from $B C$}

To assess the bLF loading capacity of BC, $25 \times 170 \mathrm{~mm}$ films, obtained after purification, were immersed in $10 \mathrm{mg} \mathrm{mL}^{-1} \mathrm{bLF}$ solutions under mild agitation at RT for $24 \mathrm{~h}$. Afterwards, the films were vacuum-dried at RT for $48 \mathrm{~h}$ in a desiccator. Then, to determine the bLF release rate from the $\mathrm{BC}$ films, these were again immersed in a PBS solution at $25^{\circ} \mathrm{C}$ with mild agitation. In both assays (adsorption and desorption), aliquots were regularly collected and the bLF concentration in solution was quantified using a fast protein liquid chromatography (FPLC) apparatus (Pharmacia) with a UV-detector $(\lambda=280 \mathrm{~nm}$ ) (Knauer). Three film replicates of each type of $B C$ were used in this assay. Each sample retrieved was measured three times. The bLF release profile was adjusted to a modified Gompertz Equation (Equation (2)) (Zwietering, Jongenburger, Rombouts, \& van 't Riet, 1990) as follows:

$X(t)=X_{\max } \exp \left[-\exp \left[\frac{R_{r} e}{X_{\max }}(\psi+t)+1\right]\right]$

where, " $X(t)$ " represents the cumulative bLF release at time $(\mathrm{t})(\mathrm{mg} /$ $\mathrm{mL} . \mathrm{g})$, " $X_{\max }$ " the maximum release of $\mathrm{bLF}(\mathrm{mg} / \mathrm{mL} \cdot \mathrm{g})$, " $\mathrm{R}_{\mathrm{r}}$ " the bLF release rate $(\mathrm{mg} / \mathrm{mL} \cdot \mathrm{g} \cdot \mathrm{min})$, " $e$ " the constant equal to 2.7182818 and " $\psi$ " the latency phase (min).

\subsubsection{Swelling behaviour}

A gravimetric method based on the methodology described by Sangsanoh and Supaphol was used to determine the degree of swelling in BC samples (Sangsanoh \& Supaphol, 2006). Circular BC films with $5 \mathrm{~mm}$ diameter were used in these assays. Samples were immersed in PBS solutions at RT and were collected at regular intervals, placed between two sheets of tissue paper to remove the excess of liquid, and weighed (ADA 100). The swelling degree was calculated using the following Equation (3):

Degree of Swelling $(\%)=\frac{\left(m_{s}-m_{d}\right)}{m_{d}} \times 100$

where, " $m_{s}$ " represents the mass of the membrane after it is submersed in the PBS solution ( $\mathrm{mg}$ ) and " $m_{d}$ " the mass of the sample in is dried state $(\mathrm{mg})$.

\subsubsection{Water vapour permeability}

The water vapour transmission of all produced films was assessed gravimetrically, using an adaptation of the methodology described in the ASTM E96-95 (ASTM, 1980). BC films were placed on top of glass vials containing $1 / 3$ of ultrapure water and fixed using parafilm. Samples were equilibrated overnight in a desiccator containing silica gel at RT. Afterwards, the vials were placed in a desiccator with silica gel and fans in its interior to maintain homogenous conditions, at $25{ }^{\circ} \mathrm{C}$ as described by Cerqueira et al. (Miguel A Cerqueira, Costa, Fuciños, Pastrana, \& Vicente, 2014). The relative humidity gradient $(\mathrm{RH})$ was $0 / 100$ ( $\mathrm{RH}$ outside/RH inside). The glass vials were weighed within a 10 -h period. The WVP was calculated according to Equation (4):

$W V P=\frac{W V T \times x}{A \times P_{0} \times\left(R H_{1}-R H_{2}\right)}$

where, "WVP" is the water vapour permeability, "WVT" the mass variation rate $(\mathrm{g} / \mathrm{h})$; " $x$ " the film thickness $(\mathrm{mm}) ;$ " $A$ " the film membrane area exposed to the permeant $\left(\mathrm{m}^{2}\right)$; " $P_{0}$ " the vapour pressure of pure water $(1.359 \mathrm{kPa})$ and " $\left(R H_{1}-R H_{2}\right)$ " the relative humidity gradient used in the experiment at $25^{\circ} \mathrm{C}$.

\subsubsection{Mechanical properties}

The macroscopic physical characteristics of the $\mathrm{BC}+$ bLF films were calculated by determining the dry mass of 50 samples of each film (Adam Equipment), and by recording the thickness of 30 replicas of each film using a digital micrometre (Mitutoyo). The ultimate goal for the $\mathrm{BC}+$ bLF films is to encase meat products, which inherently possess high water activity (Borch, KantMuermans, \& Blixt, 1996). Therefore, the mechanical properties were evaluated using re-hydrated $\mathrm{BC}$ samples, using a Shimadzu Universal Testing Machine (AG-IS - load cell of $50 \mathrm{~N}$ ). Immediately prior to the stress strain tests, the films were immersed in distilled water for no less than $5 \mathrm{~min}$. The defined strain rate was $0.5 \mathrm{~mm} /$ min at RT. The maximum stress $\left(\sigma_{\max }\right)$, the elongation at break and 
the modulus of elasticity $(E)$ were determined, with the latter being calculated in the linear zone of elasticity, between 0 and $1 \%$ of strain using Hook's law (Equation (5)) in 5 samples of each film (Menard, 2008).

$\sigma=E \varepsilon$

where, " $E$ " is the elastic modulus (MPa), " $\sigma$ " the strain (MPa) and " $\varepsilon$ " the stress of uniaxial deformation (\%).

\subsection{Bactericidal activity characterization}

The antibacterial properties of the $\mathrm{BC}+$ bLF edible films were assessed against $E$. coli and $S$. aureus kindly provided by the Faculty of Pharmacy of University of Porto (Porto, Portugal).

\subsubsection{Specific growth rate impact analysis}

In order to evaluate the influence of bLF in the specific growth rate of the model microorganisms, culture flasks containing NB with $0,0.25,0.5,1,2.5,5$ and $10 \mathrm{mg} / \mathrm{mL}$ of bLF were inoculated with approximately $1.5 \times 10^{6} \mathrm{CFU} / \mathrm{mL}$ of either $E$. coli or $S$. aureus, and were subsequently incubated at $37^{\circ} \mathrm{C}$ with $120 \mathrm{rpm}$ of orbital shaking. Additionally, BC + bLF disks (and controls consisting of BC without bLF) with $22 \mathrm{~mm}$ diameter were aseptically introduced in culture flasks containing NB medium $(4.5 \mathrm{mg}$ of BC disks per $\mathrm{mL}$ of culture medium) and these were incubated using equivalent inoculum and culture conditions, as previously stated. For all the tested flasks, the optical density $(\lambda=600 \mathrm{~nm})$ was registered every hour.

\subsubsection{Live/dead viability and scanning electron microscopy (SEM) analysis}

NB inoculated with approximately $1.5 \times 10^{6} \mathrm{CFU} / \mathrm{mL}$ of either E. coli or S. aureus, was poured on top of BC + bLF disks, with $5 \mathrm{~mm}$ and $22 \mathrm{~mm}$ diameter, inside 96 and 24 well plates respectively, and these were afterwards incubated at $37^{\circ} \mathrm{C}$ and $150 \mathrm{rpm}$ for $4 \mathrm{~h}$. The $5 \mathrm{~mm}$ disks were used in a Live/Dead viability assessment. Before each of the following step, the films were gently rinsed with PBS as follows: the culture medium was removed and then the disks were immersed for $10 \mathrm{~min}$ in propidium iodide (PI) $(0.33 \%$ (w/v) in PBS). Subsequently, the disks were submerged in a formaldehyde solution $(3.67 \%(\mathrm{v} / \mathrm{v}))$ for $10 \mathrm{~min}$ at RT to fixate the cells. Next, the disks were immersed in a PBS solution with 4',6-diamidino-2phenylindole (DAPI) $(0.01 \%(\mathrm{w} / \mathrm{v})$ in PBS) for $10 \mathrm{~min}$ and subsequently rinsed twice prior to observation on the fluorescence microscope (Olympus BX51). Images were obtained with different fluorescence filters and were further merged using ImageJ software (Schneider, Rasband, \& Eliceiri, 2012).

Scanning electron microscopy (SEM) was performed on the $22 \mathrm{~mm}$ BC disks, after cell fixation according to the procedure described by Andrade et al. (Andrade et al., 2011). Briefly, the culture media was removed and $1 \mathrm{~mL}$ of $2.5 \%(\mathrm{v} / \mathrm{v})$ glutaraldehyde in PBS was added to each sample. The disks were maintained for $1 \mathrm{~h}$ at RT to promote the fixation of the bacterial cells onto CB. Immediately after, the films were gently rinsed with distilled water and submitted to a dehydration process using serial ethanol dilutions, with increasing percentages of ethanol $(55,70,80,90,95,100 \%(v /$ v)). Samples were submerged in each solution for a period of $30 \mathrm{~min}$ at RT. Finally, the remaining ethanol in the films was evaporated at RT. The BC disks were coated with gold-sputtered (Polaron) and were observed by SEM (LEICA) with a magnification of $20,000 \times$ using an electron accelerating voltage of $5 \mathrm{kV}$.

\subsubsection{Evaluation of direct contact bactericidal effect}

The American Association of Textile Chemists and Colourists
(AATCC) test method 100-TM100 (AATCC, 2012) was herein adapted to evaluate the contact bactericidal efficiency of the $\mathrm{BC}+$ bLF films, so-called contact killing. Briefly, BC disks with $9 \mathrm{~mm}$ diameter were placed in a 48 well plate and inoculated with either $9.2 \times 10^{5} \mathrm{CFU} / \mathrm{mL}$ of $E$. coli or $9.4 \times 10^{5} \mathrm{CFU} / \mathrm{mL}$ of $S$. aureus. After $2 \mathrm{~h}$ of incubation at $37^{\circ} \mathrm{C}$, the samples were covered with $500 \mu \mathrm{L}$ of PBS, and carefully stirred for no less than $1 \mathrm{~min}$, to homogenise the bacterial population. Afterwards, the $\mathrm{CFU} / \mathrm{mL}$ was determined in $\mathrm{MH}$ agar plates incubated for $24 \mathrm{~h}$ at $37^{\circ} \mathrm{C}$. The percentage of $\mathrm{CFU}$ reduction was determined as follows (Equation (6)):

$R=\frac{A-B}{A} \times 100$

where, " $R$ " is the percentage of CFU reduction, " $A$ " the $C F U / m L$ of the inoculum, and " $B$ " the CFU/mL obtained after $2 \mathrm{~h}$ of contact with the films at $37^{\circ} \mathrm{C}$. Three disks replicas were used for each bacteria.

\subsubsection{Evaluation of $B C+$ bLF films bactericidal effect}

An adaptation of the AATCC test method 100-TM100 (AATCC, 2012) was used for the bactericidal assays of BC + bLF films using fresh sausage samples. BC disks (with and without bLF) with $22 \mathrm{~mm}$ diameter were individually placed at the bottom of sterilized flasks, under aseptic conditions, and were further inoculated with $9.5 \times 10^{5} \mathrm{CFU} / \mathrm{mL}$ of $E$. coli and $1.0 \times 10^{6} \mathrm{CFU} / \mathrm{mL}$ of $S$. aureus. Immediately after inoculation, a fresh sausage piece with $12 \mathrm{~mm}$ diameter and $1.0 \mathrm{~cm}$ of height was carefully placed on top of the inoculated area. The fresh sausage cylinder was prepared immediately before use, being exposed to UV-light for 15 min to minimize the hypothetical endogenous contamination. As a control, the same procedure was used for a $22 \mathrm{~mm}$ disk of the casing as removed from the fresh sausage. After $24 \mathrm{~h}$ of incubation at $37^{\circ} \mathrm{C}$, $5 \mathrm{~mL}$ of PBS were poured into the flasks and submitted to a vigorous agitation. The obtained $\mathrm{CFU} / \mathrm{mL}$ was determined and the percentage of reduction was calculated using the following equation:

$R(\%)=\frac{A-C}{A} \times 100$

where, " $R$ " is the percentage of CFU reduction, " $A$ " is the CFU/mL obtained immediately after inoculation, and " $C$ " is the $\mathrm{CFU} / \mathrm{mL}$ achieved after $24 \mathrm{~h}$ of incubation at $37^{\circ} \mathrm{C}$.

\subsection{Endotoxin level determination}

G. xylinus is a Gram-negative bacterium. To assure the efficiency of the $\mathrm{BC}$ purification procedure described in section 2.2, as applied to $\mathrm{BC}$ samples from different sources, the levels of endotoxin were quantified. Endotoxin determination was performed using the limulus amebocyte lysate test Pierce ${ }^{\circledR}$ LAL Chromogenic Endotoxin Quantitation kit (Thermo Scientific). The optical density was measured at $\lambda=405 \mathrm{~nm}$, with a linear range set between 0.1 and 1.0 endotoxin units (EU) $\mathrm{mL}^{-1}$.

\subsection{In vitro dynamic gastrointestinal model}

The BC films (with and without bLF) were submitted to a dynamic in vitro gastrointestinal system similar to the intestinal tract model (TIM) developed by TNO (Nutrition and Food Research, Netherlands). This system mimics the gastrointestinal peristaltic movements, allied to a dynamic transfer between the stomach, duodenum, jejunum and ileum compartments. The purpose of using this system was to determine if the edible BC films would generate cytotoxic elements during the gastrointestinal digestion. Electrolyte gastric solution was composed of $0.48 \%(\mathrm{w} / \mathrm{v}) \mathrm{NaCl}$, 
$0.22 \%(\mathrm{w} / \mathrm{v}) \mathrm{KCl}, 0.02 \%(\mathrm{w} / \mathrm{v}) \mathrm{CaCl}_{2}, 0.15 \%(\mathrm{w} / \mathrm{v}) \mathrm{NaKHCO}_{3}$ ), pepsin $600 \mathrm{U} \mathrm{mL}^{-1}$ and lipase $40 \mathrm{U} \mathrm{mL}^{-1}$, whereas the SIES (small intestine electrolyte solution) was composed of $0.5 \%(\mathrm{w} / \mathrm{v}) \mathrm{NaCl}, 0.06 \%(\mathrm{w} / \mathrm{v})$ $\mathrm{KCl}$ and $0.025 \%(\mathrm{w} / \mathrm{v}) \mathrm{CaCl}_{2}$. In all gastrointestinal compartments the $\mathrm{pH}$ was adjusted with $\mathrm{HCl}(37 \%(\mathrm{w} / \mathrm{v}))$ or $\mathrm{NaHCO}_{3}(10.6 \%(\mathrm{w} / \mathrm{v}))$.

To simulate mouth digestion, the films were submitted to a protocol described by Sessa et al. (Sessa, Tsao, Liu, Ferrari, \& Donsì, 2011). Briefly, $10 \mathrm{~mL}$ of human volunteer's saliva was collected. Edible BC films with $3 \times 8 \mathrm{~cm}$ (with and without bLF) were shredded with scissors, immersed in the saliva solution and incubated at $37{ }^{\circ} \mathrm{C}$ for $10 \mathrm{~min}$. Afterwards, $30 \mathrm{~mL}$ of PBS were added to the mixture and all contents shredded using a blender. Finally, the mixture was inserted in the gastrointestinal model. The digestion conditions were described by Reis et al. (Reis et al., 2008). with some modifications. In the stomach compartment, the sample contacted with the gastric solution added at a flow rate of $0.33 \mathrm{~mL} /$ min. The $\mathrm{pH}$ was gradually dropped from the initial 7.4 , to 4.5 at $5 \mathrm{~min}, 4.2$ at $20 \mathrm{~min}, 2.8$ at $40 \mathrm{~min}, 2.1$ at $60 \mathrm{~min}, 1.8$ at $90 \mathrm{~min}$, and finally kept 1.7 after $120 \mathrm{~min}$ of digestion, to mimic the process occurring after food ingestion. Then, the stomach compartment was gradually emptied. In the duodenum compartment, the samples were exposed to SIES enriched with $7 \%(\mathrm{w} / \mathrm{v})$ pancreatin and $4 \%(\mathrm{v} / \mathrm{v})$ bile at a flow rate of $0.6 \mathrm{~mL} / \mathrm{min}$. The $\mathrm{pH}$ was maintained at 6.5 and the duodenum was gradually emptied. When the sample reached the jejunum, it was mixed with SIES with $10 \%$ bile $(\mathrm{v} / \mathrm{v})$ added at a flow rate of $2.13 \mathrm{~mL} / \mathrm{min}$, and the $\mathrm{pH}$ was maintained at 6.8. The jejunum compartment was gradually emptied. In the ileum, the added solution consisted solely of SIES, added at $2.0 \mathrm{~mL} /$ min and the $\mathrm{pH}$ value was maintained at 7.2. After $3 \mathrm{~h}$, all the volume present in the ileum was collected, immediately frozen at $-80^{\circ} \mathrm{C}$, and stored until further use.

\subsection{Cell viability assessment}

The potential cytotoxicity of the $\mathrm{BC}$ and $\mathrm{BC}+$ bLF films before and following passage through an in vitro gastrointestinal system was evaluated with 3T3 mouse embryo fibroblasts (ATCC CCL-164). To test the $\mathrm{BC}$ and $\mathrm{BC}+$ bLF films per se cells were seeded at a density of $1.3 \times 10^{5}$ cells per well, on top of each BC sample previously placed on the bottom of 24 well plates. Fibroblasts were incubated in Dulbecco's Modified Eagle's medium (DMEM) (Biochrom), with $10 \%(\mathrm{v} / \mathrm{v})$ fetal bovine serum (FBS) (Invitrogen) and $1 \%$ $(\mathrm{v} / \mathrm{v})$ of penicillin/streptomycin at $37{ }^{\circ} \mathrm{C}$ in a $5 \% \mathrm{CO}_{2}$ humidified atmosphere. Cells grown directly on the polystyrene surface were used as control. The cell growth was followed for $72 \mathrm{~h}$. At this time, BC films were washed with PBS to remove non-adhered cells, and were further incubated with trypsin to recover the adhered cells. The total number of fibroblasts adhering onto the BC samples was quantified in a Neubauer chamber, using trypan blue (ratio 1:1) (Flücka) to distinguish viable from non-viable (blue) cells.

Additionally, the trypan blue exclusion assay was used to test the digestion fluids that resulted from the simulated gastrointestinal digestion of the BC films (with and without bLF). The frozen samples previously collected from the ilium were thawed and filter sterilized using a $0.2 \mu \mathrm{m}$ filter. 96 well plates were used to seed 3T3 cells at a density of $1.3 \times 10^{5}$ cells/well. Cells were left to adhere in the polystyrene surface for $24 \mathrm{~h}$ and afterwards were exposed to the diluted (1/5) degradation products (section 2.7) in culture media for $72 \mathrm{~h}$. Control samples cells were exposed to a diluted (1/ 5) PBS and small intestinal electrolyte solution (SIES). Afterwards, cells were washed with PBS and trypsinized. Cells suspension was then added at a 1:1 ratio to trypan blue and viable/non-viable cells were determined. All experiments were conducted in triplicate.

\subsection{Statistical analysis}

All data are presented as the mean \pm standard error of the mean. Statistical analysis included t-test, one-way ANOVA and twoway ANOVA with Tukey post-hoc tests whenever the analysed results displayed a parametric distribution, otherwise Kurskal-Wallis with a Dunn's post hoc test was used. All statistical analysis was performed using Statistica 8.0 software (Statsoft, Inc.) using an alpha value of 0.05 .

\section{Results and discussion}

In this work, BC from two distinct sources was studied for its bLF adsorption ability and saturation limit. Its functionality (antimicrobial activity) and cytotoxicity was also evaluated.

\subsection{BC edible films physicochemical characterization}

\subsubsection{Prussian blue staining of $B C+b L F$ films}

A simple methodology to functionalize the $B C$ films consists on the adsorption of bLF onto the $\mathrm{BC}$ nanofibrillar network. Determining the concentration of bLF in the supernatant, although allowing to quantitatively inferring as to the amount of adsorbed protein, it does not provide information regarding the distribution profile of the protein within the 3D nanofibrillar BC matrix. Therefore, a Prussian blue formation analysis was performed on both BC1 and BC2 films to qualitatively ascertain such distribution of the adsorbed protein within the 3D matrix. The bLF used possesses $120 \mathrm{ppm}$ of $\mathrm{Fe}^{3+}$ in its iron binding clefts, thus its presence should lead to Prussian blue formation (according to Equation (1)). The transversal cuts analysed by stereo microscopy showed that BC films solely exposed to PBS did not display the characteristic coloration originated by the Prussian blue (Fig. 1Aa) and b)), whereas BC films with adsorbed bLF, were heavily stained throughout all the BC matrices (Fig. 1Ac) and d)).

\subsubsection{Ultraviolet-visible spectroscopy and Fourier transform infrared spectroscopy with attenuated total reflectance}

The presence of bLF was further analysed by UV-vis and FTIR spectrometry. In both $\mathrm{BC} 1+$ bLF and $\mathrm{BC} 2+$ bLF, the typical absorbance peak of bLF is easily identifiable at $295 \mathrm{~nm}$, due to its tyrosine residues involved in metal complexation (Fig. 1B) (Aisen \& Leibman, 1972; Belitz \& Grosch, 1999). The high absorption peaks visible between 230 and $200 \mathrm{~nm}$ in the BC films with absorbed bLF also correspond to histidine, cysteine, methionine and aromatic amino acid residues (Belitz \& Grosch, 1999). In BC samples, the sharp and steep band from FTIR-ATR spectra (Fig. 1C), at approximately $1060 \mathrm{~cm}^{-1}$, corresponds to the $\mathrm{C}-\mathrm{O}-\mathrm{C}$ stretching. The low intensity band found near the $2890 \mathrm{~cm}^{-1}$ corresponds to the aliphatic $\mathrm{C}-\mathrm{H}$ stretching, and finally, the broad band of $\mathrm{O}-\mathrm{H}$ stretching vibration is present at approximately $3350 \mathrm{~cm}^{-1}$ (Müller et al., 2012). BC1 + LF and BC2 + LF exhibit two characteristic amide adsorption bands at around $1530 \mathrm{~cm}^{-1}$ and $1640 \mathrm{~cm}^{-1}$, corresponding to the Amide II ( $\mathrm{C}-\mathrm{N}$ bending and $\mathrm{N}-\mathrm{H}$ bending) and Amide I ( $C=0$ stretching), respectively. The Amide III $\left(1240 \mathrm{~cm}^{-1}\right)$ and the $\mathrm{C}-\mathrm{O}$ stretching from the $\mathrm{COO}^{-}$could not be identified in the bLF/BC films. Moreover, the Amide A $\left(3280 \mathrm{~cm}^{-1}\right)$ band is probably masked by the cellulose $\mathrm{O}-\mathrm{H}$ stretching (Xavier, Chaudhari, Verma, Pal, \& Pradeep, 2010).

\subsection{3. bLF adsorption-desorption profile onto and from $B C$}

Analysis on the adsorption/desorption profile allowed estimating the saturation limit of bLF for both types of BC samples. It's noteworthy to mention that in previous experiments, following protein adsorption in never-dried BC films, we observed no 
A
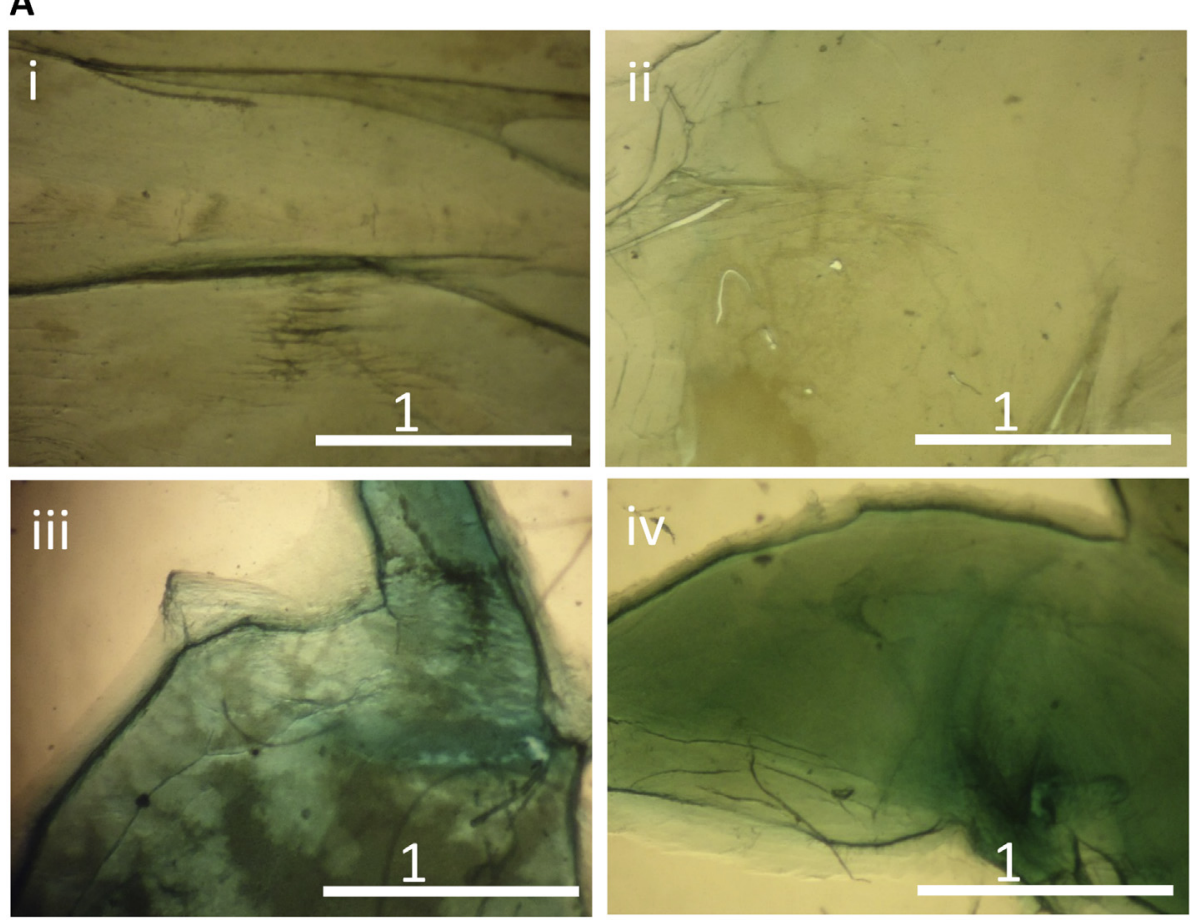

B
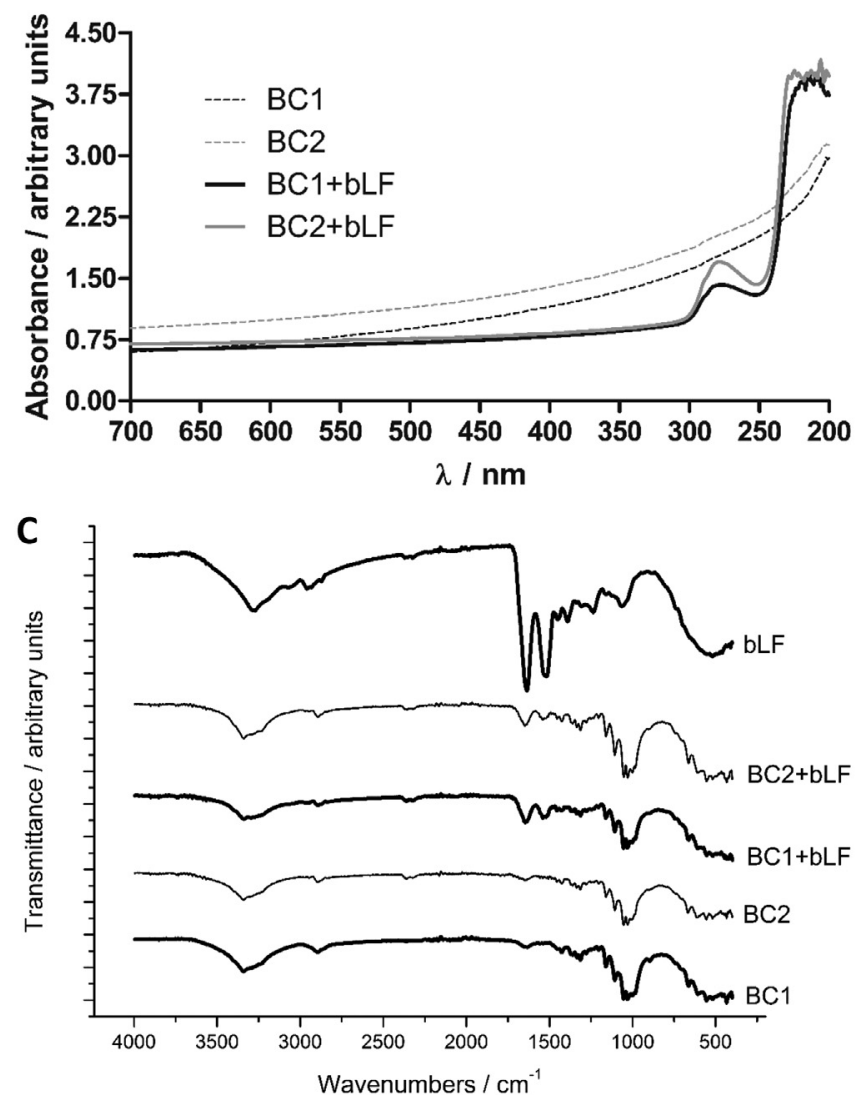

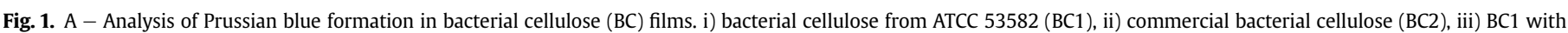

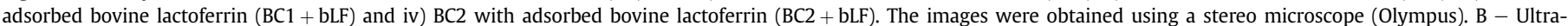

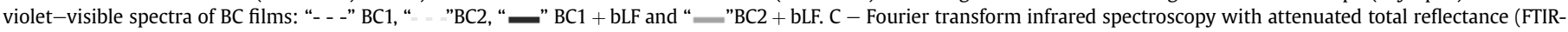
ATR) of bovine lactoferrin powder (bLF), "BC1", "BC2", "BC1 + bLF"and "BC2 + bLF". 
significant differences ( $\mathrm{t}$ test, $p<0.05$ ) in the protein desorption profile, between the dried and never-dried samples, thus suggesting the rehydration of the dried films was enough to promote a protein desorption comparable to the never-dried films. Therefore, we herein present the adsorption/desorption profiles only with the never-dried samples (further discussion on the swelling behaviour of the BC samples is given below). Fig. 2A shows that both BC films present a similar cumulative adsorption profile, divided in 3 phases, namely an initial adsorption phase, of up to $1 \mathrm{~h}$ of incubation for $\mathrm{BC} 1$ and up to $0.33 \mathrm{~h}$ for $\mathrm{BC} 2$; this was followed by a step increase (second phase) until the highest concentration plateau is achieved (third phase), after approximately $4 \mathrm{~h}$ incubation, reached simultaneously by both types of BC films. The sharp bLF adsorption rate was roughly estimated as 4.4 and $6.4 \mathrm{mg} / \mathrm{mL}$.h for $\mathrm{BC} 1$ and $\mathrm{BC} 2$, respectively. After $24 \mathrm{~h}$ of incubation, the adsorbed bLF per gram of BC1 was $31.8 \mathrm{mg} / \mathrm{mL}$; while BC2 adsorbed $40.6 \mathrm{mg} / \mathrm{mL}$. This difference between the two types of $\mathrm{BC}$ was found to be statistically significant ( $\mathrm{t}$ test, $p<0.05$ ).

The in vitro release profiles obtained were adjusted using a modified Gompertz model (Equation (2)) (Fig. 2B), due to its' adequate fitness (Dash, Murthy, Nath, \& Chowdhury, 2010). The fitting values for the release profile are presented on Table 1. A significant difference is registered in the cumulative release of bLF at $20 \mathrm{~min}$, as well as at $1440 \mathrm{~min}$, with the highest value corresponding to $\mathrm{BC} 2$ ( $t$ test, $p<0.001$ ). BC2 seems to uptake a higher

A

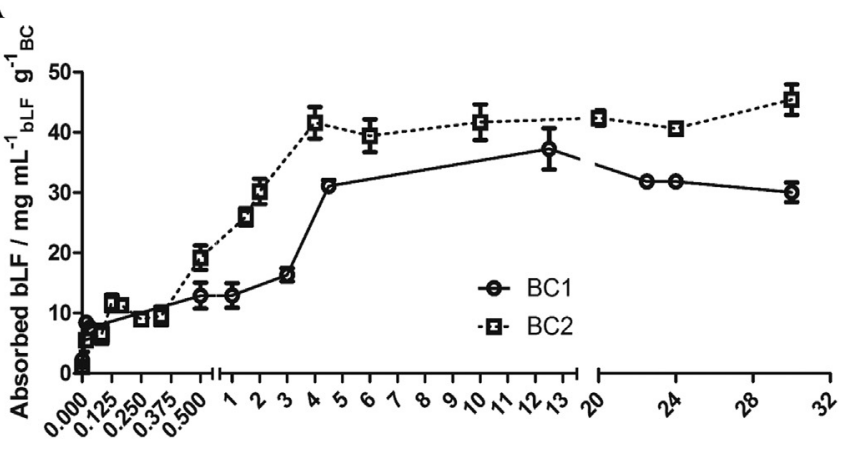

B

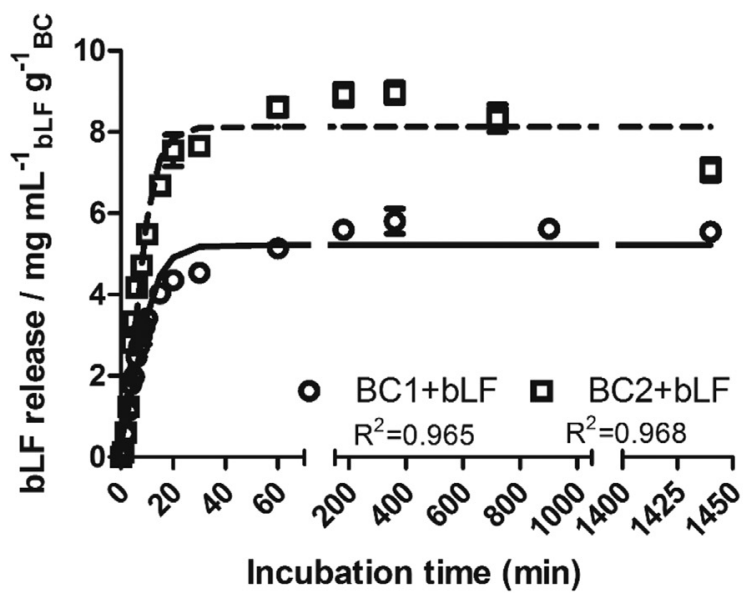

Fig. 2. A - Adsorption profiles of bovine lactoferrin (bLF) by: “-”bacterial cellulose membranes from ATCC 53582 (BC1), and “. $\mathbf{x}$-"commercial bacterial cellulose BC2. B Cumulative release profiles of bLF from BC samples: "o" bLF cumulative release from BC1 films (BC1 + bLF), “ם" cumulative release of bLF from BC2 films (BC2 + bLF), “-“ bLF release adjusted by Equation (2) for BC1 and "- - " bLF release adjusted by Equation (2) for BC2. All values correspond to the mean \pm standard error of nine independent assays $(\mathrm{n}=9)$.
Table 1

Bovine lactoferrin (bLF) release values estimated using a modified Gompertz model (Equation (2)), " $\mathrm{X}_{\max }$ " maximum bLF cumulative release, " $\mathrm{R}_{\mathrm{r}}$ " rate of bLF release and " $\psi$ " lag period prior to the bLF release.

\begin{tabular}{lll}
\hline & BC1 + bLF & BC2 + bLF \\
\hline$X_{\max }\left(\mathrm{mg} / \mathrm{mL}_{\mathrm{bLF}} \cdot \mathrm{g}_{\mathrm{BC}}\right)$ & 5.2 & 8.1 \\
$\mathrm{R}_{\mathrm{r}}\left(\mathrm{mg} / \mathrm{mL} L_{\mathrm{bLF}} \cdot \mathrm{g}_{\mathrm{BC}} \cdot \mathrm{min}\right)$ & 0.4 & 0.7 \\
$\psi(\mathrm{min})$ & 0.0 & 0.8 \\
\hline
\end{tabular}

amount bLF and also to release a higher concentration of bLF. However, both BC films released almost the same relative amount of absorbed bLF, $18.5 \%$ and $17.3 \%$ for $\mathrm{BC} 1$ and $\mathrm{BC} 2$, respectively. The release rate of $\mathrm{BC} 2$ is however, slightly higher than $\mathrm{BC} 1$.

\subsubsection{Swelling behaviour}

$\mathrm{BC}$ high water binding capacity may confer advantages to the encased food, such as the prevention of dripping and the reduction of water condensation in the outer casing, thus improving product presentation and concomitantly, the consumer acceptance (Gennadios, Hanna, \& Kurth, 1997). Moreover, it prevents the loss of moisture, hence reducing the loss of commercial weight value. The direct contact with a food product that has high water content such as meat will induce the swelling of $\mathrm{BC}$ films during the uptake of water molecules. Therefore, the estimation of the rate of swelling from BC films is crucial if considering their use as a packaging system. However, with $\mathrm{BC}$, the drying process may reduce the plasticizing effect of the water molecules, by increasing the proximity of neighbour BC fibrils and promoting the strong formation of additional hydrogen bounds (Clasen, Sultanova, Wilhelms, Heisig, \& Kulicke, 2006; Lin, Hsu, Chen, \& Chen, 2009). Consequently, rehydration may be inhibited by a more aggregated BC nanofibrillar structure. Thus, on one hand, the water holding capacity of the dried $B C$ films will never be equivalent to the never-dried $B C$ membranes; on the other hand, this could affect bLF desorption. In this work, all BC films showed a swelling value ranging between approximately $215 \%$ and $380 \%$ just after 90 s of immersion in PBS (Fig. 3). For BC without protein, these values are actually significantly higher than the approximately $80 \%$ reported by Rambo et al. for BC from G. xylinus ATCC 23769 (Rambo et al., 2008). BC1, BC2

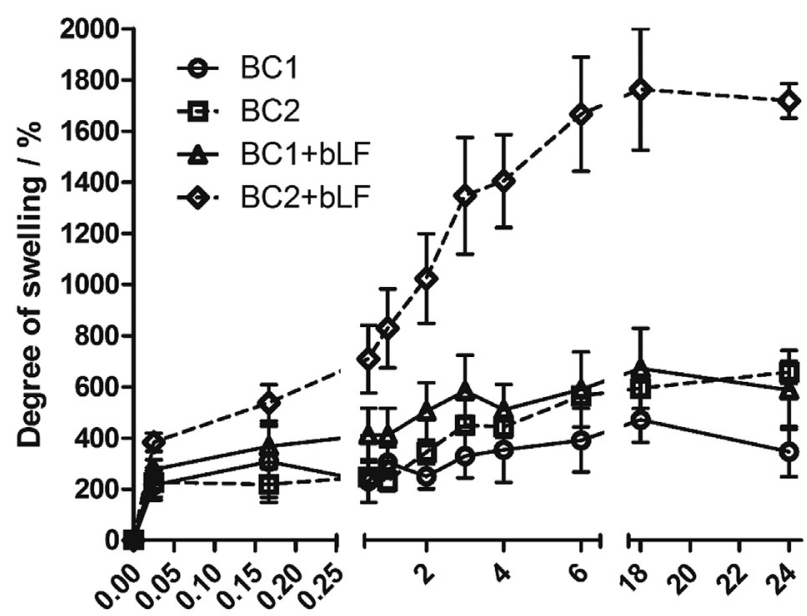

Incubation time / $\mathbf{h}$

Fig. 3. Profile of the degree of swelling: "๑"bacterial cellulose from ATCC 53582 (BC1), “. $\mathbf{- 7 . " c o m m e r c i a l ~ b a c t e r i a l ~ c e l l u l o s e ~ ( B C 2 ) , ~ " ~}-\mathbf{\Delta}$ " BC1 with adsorbed bovine lactoferrin (BC1 + bLF) and "ه" BC2 with adsorbed bovine lactoferrin (BC2 + bLF). The values represent the mean \pm standard error of three independent assays $(n=3)$. 
and $\mathrm{BC} 1+\mathrm{bLF}$ share the same swelling profile. $\mathrm{BC} 2+\mathrm{bLF}$ in particular has a quite distinct profile, characterized by a second increase phase of approximately $205 \% \mathrm{~h}^{-1}$, subsequent to the $90 \mathrm{~s}$, that subsists up to $24 \mathrm{~h}$ of immersion. This may be due to the higher protein loading capacity exhibited by $\mathrm{BC} 2+$ bLF that, by further coating the surface of $\mathrm{BC}$ fibres, the adsorbed protein probably prevents the formation of hydrogen bonds between BC fibrils, during dehydration. Consequently, this provides more freedom for water molecules to rehydrate the $\mathrm{BC}$ matrix and ultimately leads to a higher swelling profile.

\subsubsection{Water vapour permeability}

One essential feature of edible films is their permeability to water vapour. In order to avoid the loss of moisture and consequently the weight loss of several types of meats and sausages, casings with low permeability to water vapour are used in the food industry. Fresh sausage is usually produced at ambient temperature, using fresh meat mixed with spices, remaining uncooked throughout all manufacturing process (Cruz, 2010). Due to their characteristic hydrophilic nature, polysaccharides and proteins usually offer poor water vapour permeability (Lacroix, 2009). The WVP values exhibited by the BC films were approximately 5 fold lower than those of the pig's small intestine casing (Fig. 4). The WVP values herein determined were found to be similar for $\mathrm{BC} 1$, $\mathrm{BC} 2$ and $\mathrm{BC} 2+$ bLF. BC1 + bLF possess a higher value; however, as observed in section 3.1.4, BC2 + LF exhibit a higher swelling behaviour.

The WVP values of BC are approximately three fold lower than those of other bio-based edible films, such as chitosan (Cerqueira, Souza, Teixeira, \& Vicente, 2012; Martins, Cerqueira, \& Vicente, 2012), $\kappa$-carrageenan mixed with locust bean gum (Cerqueira et al., 2014), 7 fold higher when compared to whey protein films (Fang, Tung, Britt, Yada, \& Dalgleish, 2002) and cassava starch (Henrique, Teófilo, Sabino, Ferreira, \& Cereda, 2007), but it is similar to high molecular weight methylcellulose edible films (Chambi \& Grosso, 2011; Nazan Turhan \& Şahbaz, 2004; Park, Weller, Vergano, \& Testin, 1993). These results suggest that BC may present a technical advantage in comparison to pig small intestine casing, by its improved maintenance of the products moisture content, while possibly allowing the release of water during the cooking process, thus maintaining the integrity of the casing.

\subsubsection{Mechanical properties}

The pig's small intestine casing (control) was approximately 3.5

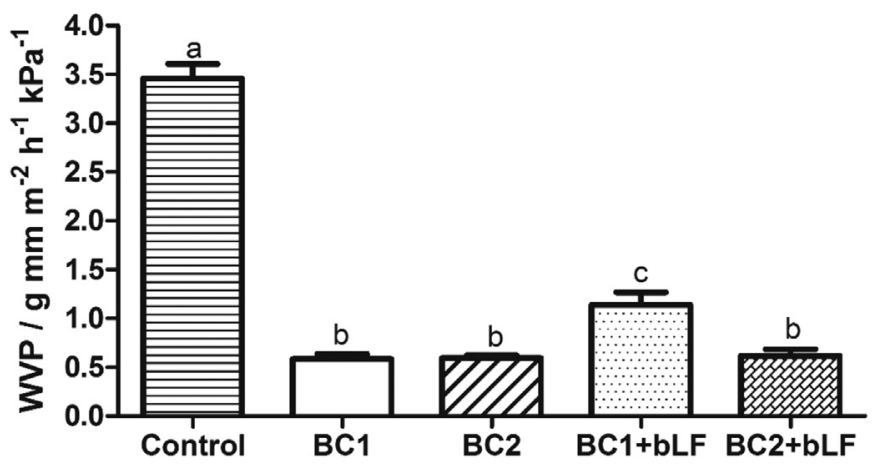

Fig. 4. Water vapour permeability (WVP) values of: "曰" pig small intestine casing (control), “口”bacterial cellulose from ATCC 53582 (BC1), “ $\square$ ”commercial bacterial

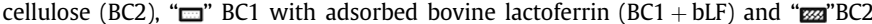
with adsorbed bovine lactoferrin $(B C 2+b L F)$. The results correspond to the mean \pm standard error of five independent assays $(n=5)$. Different letters between distinct columns denote significant differences using two-way ANOVA with Tukey post-hoc test $(\mathrm{p}<0.05)$. fold thicker than the $\mathrm{BC}$ substrates, while no pronounced differences were observed among the $\mathrm{BC}$ membranes thickness (Fig. 5A). The volumetric mass density of all $B C$ substrates was similar (Fig. 5B). The density values of BC and BC with bLF were similar to the $0.99 \mathrm{mg} / \mathrm{mm}^{3}$ density value reported by Yamanka and coworkers (Yamanaka et al., 1989).

A food casing must be able to endure the sausage filling process without bulging. Thus, the evaluation of the mechanical properties constitutes a key characterization step. In this work, the food product used has high moisture content. Additionally, it is stored in a liquid filled package. Therefore, the assessment of the mechanical properties was performed under water saturating conditions. The mechanical properties and the typical strain profiles are presented in Table 2 and Fig. $5 \mathrm{C}$, respectively. All BC films have a $\sigma_{\max }$ within the range described by the literature (Rambo et al., 2008). BC1 and $\mathrm{BC} 2$ 's behaviour towards tensile traction is relatively distinct. BC1 has an elastic modulus $(E)$ approximately 4 fold higher than that of $\mathrm{BC} 2$. Also, $\mathrm{BC} 2$ elongation at break was found to be over three times higher than that of $\mathrm{BC} 1$. bLF absorption into $\mathrm{BC}$ matrixes influenced in the same extent, the performance of both types of $\mathrm{BC}$, due to the plasticizing effect of water, which increases the strain at break and is in accordance with other studies reported in the literature. For instance, Zhu and co-workers (Zhu et al., 2010) showed a similar influence on the mechanical properties, following functionalization of BC films with $\varepsilon$-PL.

The fresh sausages casing was removed from the sausages immediately before conducting the mechanical assays. These cases consist of the small intestine and showed a considerable lower elasticity modulus, 14 fold lower when compared to BC1. These differences were less evident when compared to BC1 + bLF and $\mathrm{BC} 2+\mathrm{bLF}$, although it still was 9 fold and 2.5 fold lower, respectively. The control's maximum tensile strength is similar to that of $\mathrm{BC} 1$, and roughly 2 fold higher than that of $\mathrm{BC} 2+\mathrm{bLF}$. These values are in accordance to the maximum tensile values reported for pig's intestine (43.3 $\mathrm{MPa}$ ) and collagen $(34.8 \mathrm{MPa}$ ) casings (Cagri, Ustunol, Osburn, \& Ryser, 2003).

\subsection{Bactericidal characterization}

\subsubsection{Specific growth rate impact analysis}

The non-specific bactericidal properties of bLF have been widely described in the literature (Rossi et al., 2002; Sanchez, Calvo, \& Brock, 1992; Vorland et al., 1998). E. coli, Gram-negative bacilli, are a major representative of the normal intestinal microflora; also they are one of the most frequent causative agents of intestinal infections (Gadó et al., 1991) and thus considered important foodborne pathogen. S. aureus, Gram-positive cocci, are a recurrent agent of food poisoning (Bellamy et al., 1992).

The effect of bLF concentration on the specific growth rate $(\mu)$ of E. coli and S. aureus in NB culture medium is illustrated in Fig. 6A (for the sake of clarity, the right hand side of the figure contains the time-scale corresponding to the exponential growth phase, which allowed the determination of the $\mu$ values and their statistical comparison). As compared to the control, bLF concentrations of $5 \mathrm{mg} / \mathrm{mL}$ and $10 \mathrm{mg} / \mathrm{mL}$ were found to significantly impair the growth of $E$. coli whereas all the tested concentrations also significantly reduced the specific growth rate of $S$. aureus.

Unmodified BC disks were incubated in NB media and the growth profiles were analysed. As shown in Fig. 6B, overall, BC per se did not significantly affect the growth profile of both strains, as compared to the control. Considering the modulated release profile displayed in Fig. 2B and the films density (Fig. 5B), the expectable bLF release into the culture media would be of approximately $0.8 \mathrm{mg} / \mathrm{mL}$ in $\mathrm{BC} 1+\mathrm{bLF}$ and $\mathrm{BC} 2+$ bLF. Therefore, the expectable impact on the specific growth rate should be similar to that of $1 \mathrm{mg} /$ 

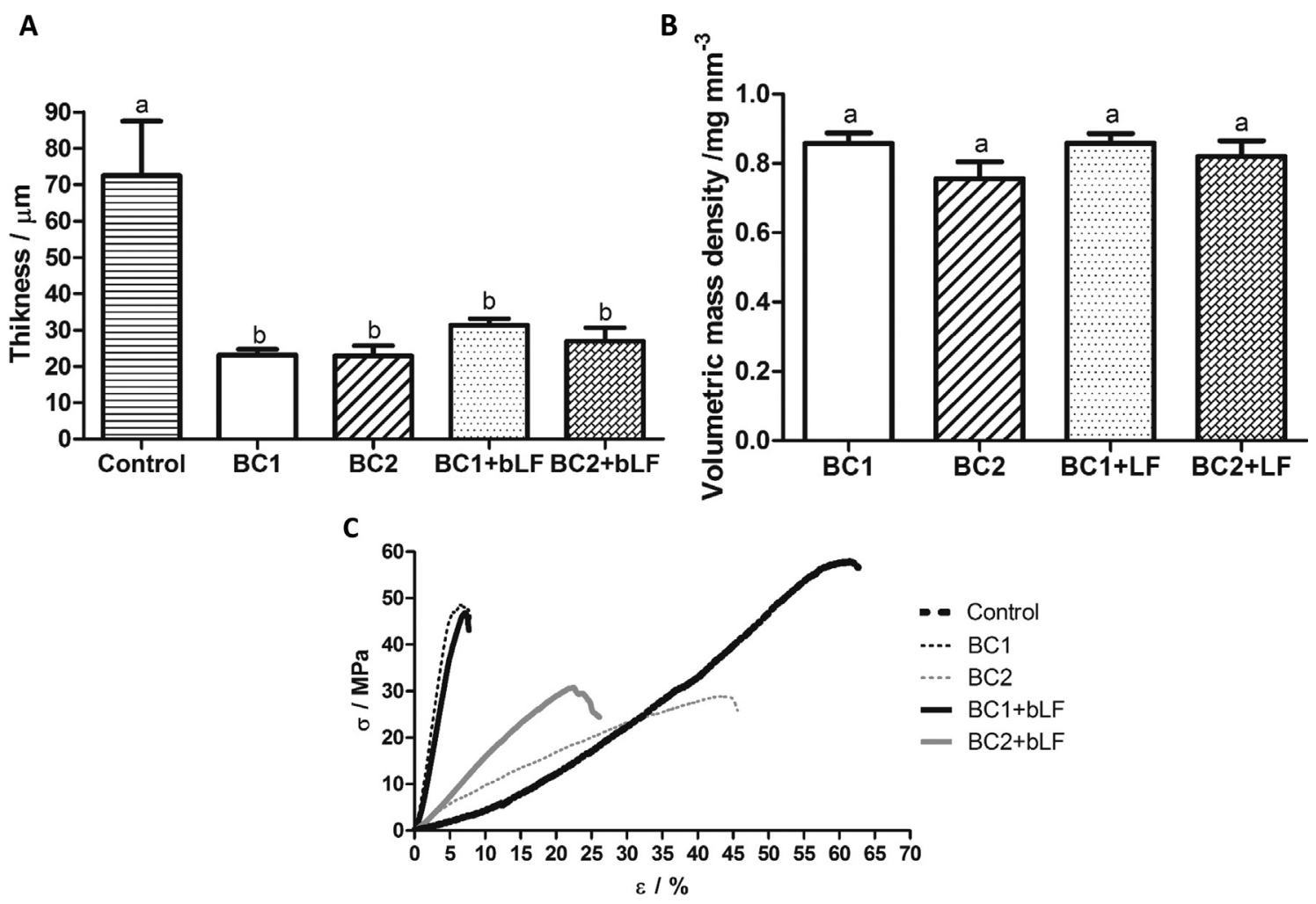

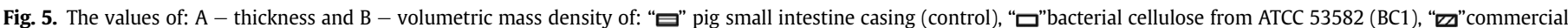

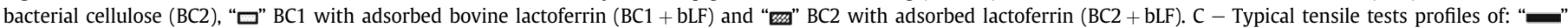

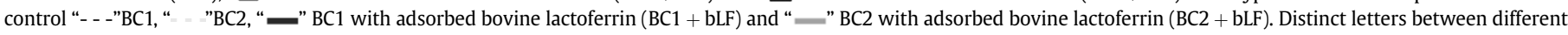

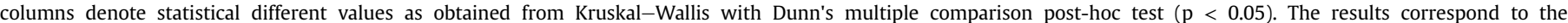
mean \pm standard error from (A) thirty five independent assays $(n=35)$ and $(B)$ seventy independent assays $(n=70)$.

Table 2

"E" elastic modulus, " $\sigma_{\max }$ " maximum stress and elongation at break " $\varepsilon_{\text {break" }}$ of: "control" fresh sausage's porcine small intestine casing, "BC1" bacterial cellulose from ATCC 53582, "BC2" commercial bacterial cellulose, "BC1 + bLF" BC1 with bLF and "BC2 + bLF" $\mathrm{BC} 2$ with bLF. The results correspond to the mean \pm standard error from five independent assays $(n=5)$.

\begin{tabular}{lclr}
\hline & $E(\mathrm{MPa})$ & $\sigma_{\max }(\mathrm{MPa})$ & \multicolumn{1}{c}{$\varepsilon_{\text {break }}(\%)$} \\
\hline Control & $46.1 \pm 9.7$ & $55.7 \pm 4.2$ & $42.5 \pm 6.5$ \\
BC1 & $643.3 \pm 35.9$ & $54.9 \pm 8.4$ & $8.1 \pm 0.5$ \\
BC2 & $153.4 \pm 44.7$ & $36.7 \pm 4.4$ & $27.8 \pm 8.8$ \\
BC1 + bLF & $433.0 \pm 100$ & $41.7 \pm 4.6$ & $7.6 \pm 0.3$ \\
BC2 + bLF & $114.5 \pm 24.5$ & $25.6 \pm 3.6$ & $24.7 \pm 1.1$ \\
\hline
\end{tabular}

$\mathrm{mL}$ bLF, which was $0.85 \mathrm{~h}^{-1}$ for E. coli and $0.51 \mathrm{~h}^{-1}$ for $S$. aureus. $E$. coli showed this growth rate when cultured with $\mathrm{BC} 1+\mathrm{bLF}$ although, comparing to the control, it did not display a significant difference. E. coli cultured with $\mathrm{BC} 2+$ bLF presented a growth rate of $0.48 \mathrm{~h}^{-1}$, which was not statistically significant when compared to the control. In the case of $S$. aureus, the growth rate values are lower than the ones expected when grown in $\operatorname{BC} 1+\operatorname{bLF}\left(0.39 \mathrm{~h}^{-1}\right)$ and higher for the BC2 $+\operatorname{bLF}\left(0.70 \mathrm{~h}^{-1}\right)$.

Microorganisms are usually prone to adhere to surfaces. In the case of $\mathrm{BC}+$ bLF films, it is possible that the adhering bacteria became exposed to higher bLF concentrations (during swelling of $\mathrm{BC}$ and leaching of bLF), thus leading to a greater reduction of the growth rate (Shimazaki et al., 1993). However, this effect may have not occurred in a reproducible manner in all experiments using $\mathrm{BC}+$ bLF films.

Optical density measurements of biomass provide an indication of the bacterial growth, however they do not allow obtaining information on the bacterial viability (Reller, Weinstein, Jorgensen, \& Ferraro, 2009). Thus, an analysis of the bacteria viability was also done by conducting a live/dead assay as described below.

\subsubsection{Live/dead viability and scanning electron microscopy (SEM) analysis}

SEM images of the BC films cultured with either E. coli or $S$. aureus, revealed an evident difference in the bacteria's morphology present at their surfaces (Fig. 7A). Clearly, the $\mathrm{BC} 1+\mathrm{bLF}$ and $\mathrm{BC} 2+\mathrm{bLF}$ surfaces are covered with disrupted bacteria debris from E. coli (Fig. 7A iii), iv)) and S. aureus (Fig. 7A vii), viii)), thus confirming the bactericidal effect of bLF. Some $S$. aureus death could also be visualized in BC2 films (Fig. 7A vi)). The live/ dead assessment test (Fig. 7B) showed a higher killing ratio (red cells) for BC with bLF as compared to BC without bLF.

\subsubsection{Bactericidal effect of $B C$ films}

The BC bactericidal efficiency was quantified using a high inoculum and optimal growth conditions for the tested bacteria. $\mathrm{BC} 1+\mathrm{bLF}$ and $\mathrm{BC} 2+\mathrm{bLF}$ showed a significant $E$. coli CFU reduction when compared to the reduction exhibited by $\mathrm{BC} 1$ and $\mathrm{BC} 2$ (Fig. 8A, i)). Indeed, $B C$ films alone only killed less than $10 \%$ of bacteria, whereas the $\mathrm{BC} 1+\mathrm{bLF}$ and $\mathrm{BC} 2+\mathrm{bLF}$ showed a considerably higher contact killing in the range of $70 \%$ in average. Effectiveness against $S$. aureus from $\mathrm{BC} 1+\mathrm{bLF}$ and $\mathrm{BC} 2+\mathrm{bLF}$ films was (statistically) higher than that of BC1 and BC2 (Fig. 8A, ii)). However, BC films alone led to a reduction of $S$. aureus CFU by nearly $65 \%$. Also, albeit the significantly higher bLF load present in $B C 2+b L F$, no differences in the reduction of the viability of either $E$. coli or S. aureus as compared to BC1 + bLF were detected. 
A

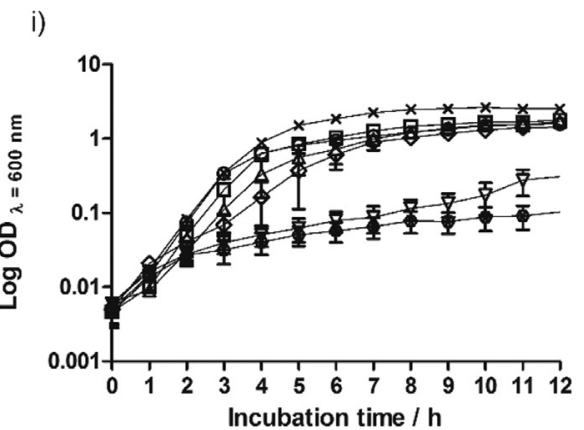

* Control $\mu=1.20 \pm 0.08 \mathrm{~h}^{-1}$ a

- $0.25 \mathrm{mg} \mathrm{mL}^{-1} \mu=0.8543 \pm 0.01 \mathrm{~h}^{-1} \mathrm{a}, \mathrm{b}$

曰 $0.5 \mathrm{mg} \mathrm{mL}^{-1} \mu=0.90 \pm 0.26 \mathrm{~h}^{-1} \mathrm{a}, \mathrm{b}$

$\triangle 1 \mathrm{mg} \mathrm{mL}^{-1} \mu=0.85 \pm 0.17 \mathrm{~h}^{-1} \mathbf{a , b}$

ii)

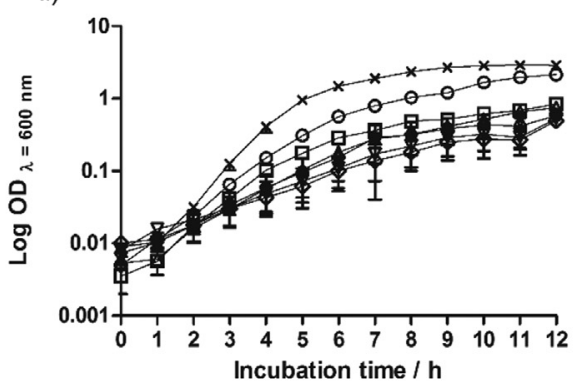

$*$ Control $\mu=1.08 \pm 0.04 \mathrm{~h}^{-1} \mathrm{a}$

- $0.25 \mathrm{mg} \mathrm{mL}^{-1} \mu=0.74 \pm 0.04 \mathrm{~h}^{-1} \mathrm{~b}$

छ $0.5 \mathrm{mg} \mathrm{mL}^{-1} \mu=0.58 \pm 0.02 \mathrm{~h}^{-1} \mathrm{~b}$

$\triangle 1 \mathrm{mg} \mathrm{mL}^{-1} \mu=0.51 \pm 0.01 \mathrm{~h}^{-1} \mathrm{~b}$

\section{B}

iii)

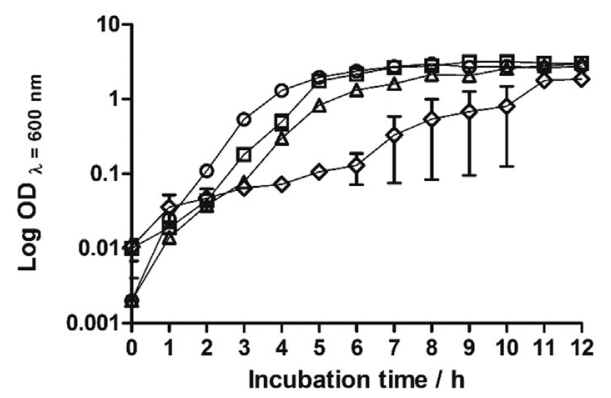

iv)

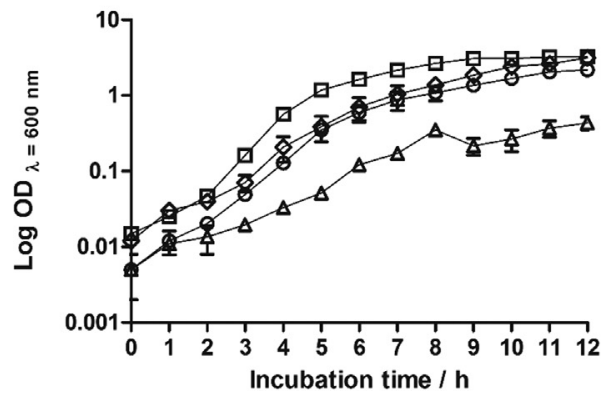

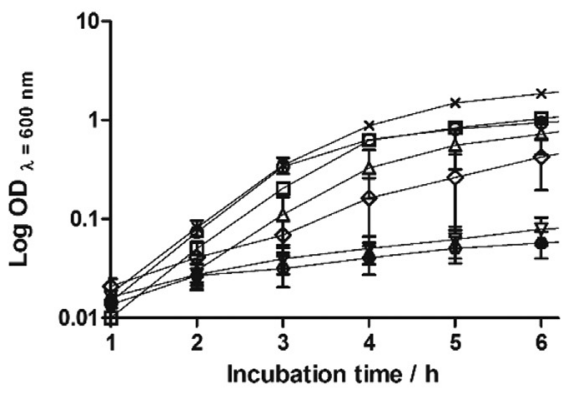

$\diamond 2.5 \mathrm{mg} \mathrm{mL}^{-1} \mu=0.81 \pm 0.07 \mathrm{~h}^{-1} \mathrm{a}, \mathrm{b}$

$\nabla 5 \mathrm{mg} \mathrm{mL}^{-1} \mu=0.36 \pm 0.09 \mathrm{~h}^{-1} \mathrm{~b}$

- $10 \mathrm{mg} \mathrm{mL}^{-1} \mu=0.53 \pm 0.08 \mathrm{~h}^{-1} \mathrm{~b}$

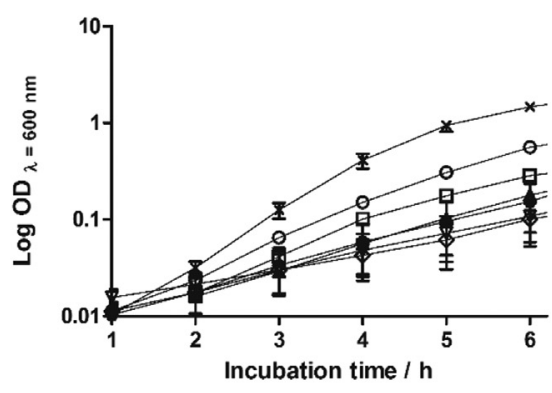

$\diamond 2.5 \mathrm{mg} \mathrm{mL}^{-1} \mu=0.47 \pm 0.07 \mathrm{~h}^{-1} \mathrm{~b}$

$\nabla 5 \mathrm{mg} \mathrm{mL}^{-1} \mu=0.40 \pm 0.04 \mathrm{~h}^{-1} \mathrm{~b}$

- $10 \mathrm{mg} \mathrm{mL}^{-1} \mu=0.53 \pm 0.08 \mathrm{~h}^{-1} \mathrm{~b}$

$$
\begin{aligned}
& \diamond \text { BC1 } \mu=1.23 \pm 0.21 \mathrm{~h}^{-1} \mathrm{a} \\
& \square \text { BC2 } \mu=1.29 \pm 0.07 \mathrm{~h}^{-1} \mathrm{a}, \mathrm{b} \\
& \triangle \text { BC1+bLF } \mu=0.86 \pm 0.14 \mathrm{~h}^{-1 \mathrm{a}, \mathrm{b}} \\
& \diamond \text { BC2+bLF } \mu=0.48 \pm 0.41 \mathrm{~h}^{-1 \mathrm{~b}}
\end{aligned}
$$

- BC1 $\mu=0.66 \pm 0.01 \mathrm{~h}^{-1} \mathrm{a}$

๑ $\mathrm{BC} 2 \mu=1.15 \pm 0.12 \mathrm{~h}^{-1} \mathrm{~b}$

$\triangle$ BC1+bLF $\mu=0.39 \pm 0.10 \mathrm{~h}^{-1} \mathrm{c}$

$\diamond$ BC2+bLF $\mu=0.70 \pm 0.04 \mathrm{~h}^{-1}$ a 


\section{A}
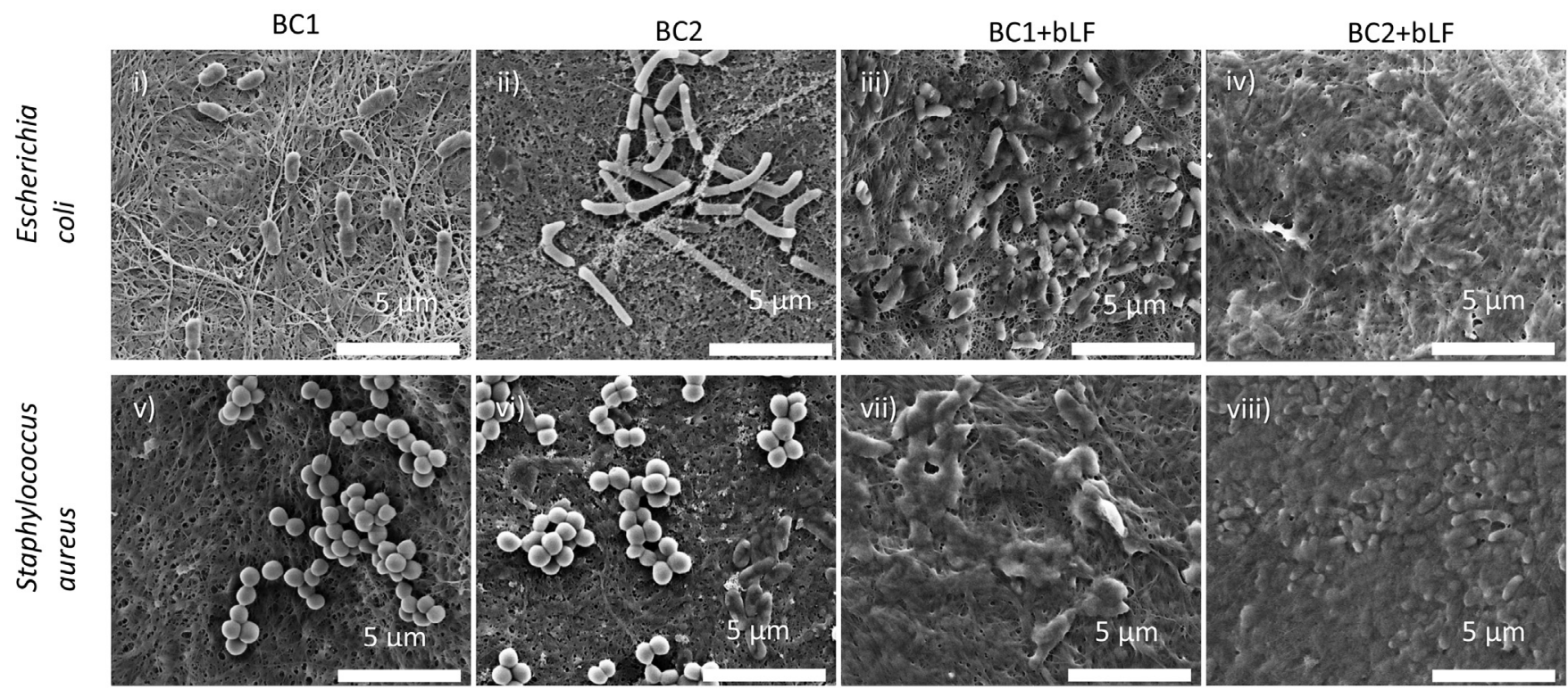

B

BC1

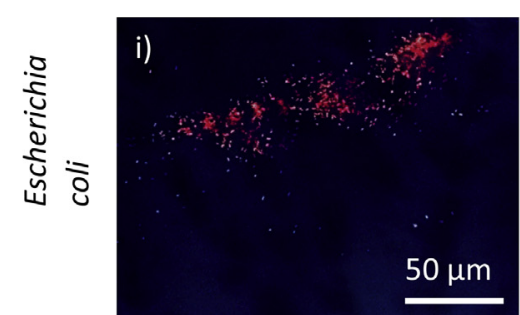

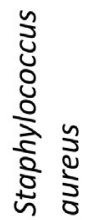

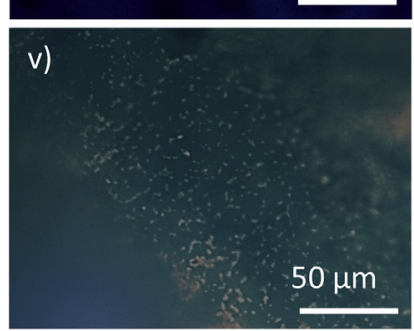

BC2
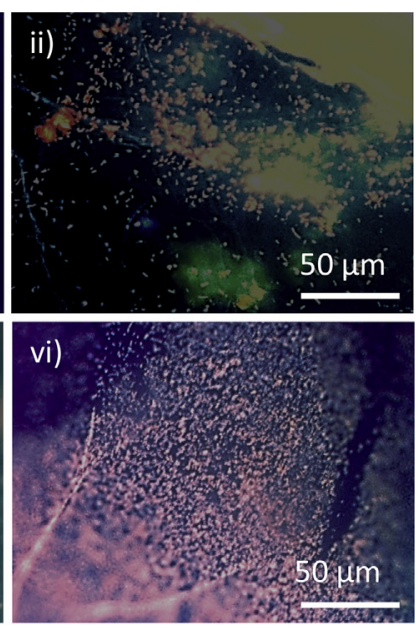

$\mathrm{BC} 1+\mathrm{bLF}$
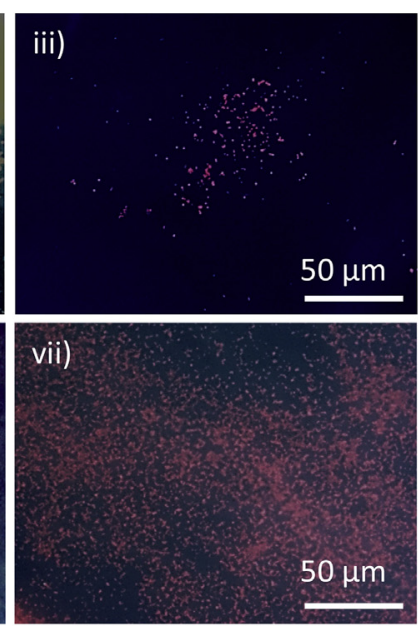

$\mathrm{BC} 2+\mathrm{bLF}$
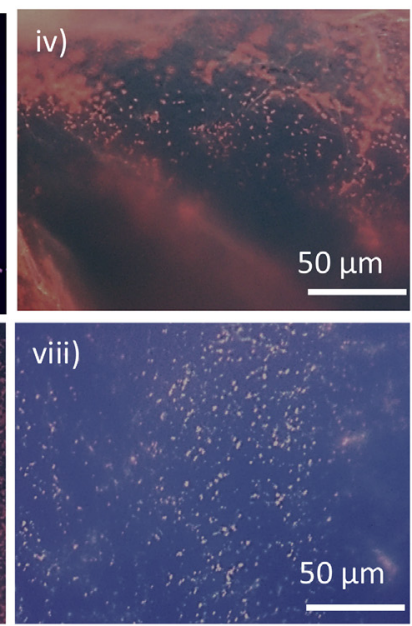

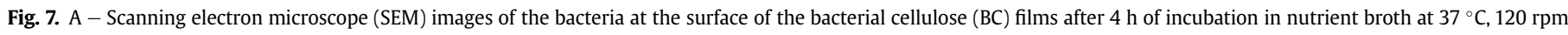
agitation: in contact with Escherichia coli and Staphylococcus aureus. B - Images from the live/dead assays with BC1, BC2, BC1 + bLF and BC2 + bLF.

BC films contaminated with bacteria were also used to wrap fresh sausage slices to further evaluate the films antibacterial efficiency through contact killing. This test aimed to evaluate the efficiency of the films under direct contact with a perishable food product. For these experiments, the contamination of the food product was induced (by adding $9.5 \times 10^{5} \mathrm{CFU} / \mathrm{mL}$ of $E$. coli and $1.0 \times 10^{6} \mathrm{CFU} / \mathrm{mL}$ of $S$. aureus). Nutrient and humidity conditions were considered adequate for microbial growth, since the microorganisms were in direct contact with the fresh sausage; also the exposure time was set to $24 \mathrm{~h}$ (Fig. 8B). Even though the assay occurred under optimal temperature conditions for microbial growth, a statistically significant reduction of viable $E$. coli was found (Fig. 8B iii)). When in contact with E. coli, BC1 and $\mathrm{BC} 2$ exhibited a similar reduction in the CFU percentage (approximately 78.5\%). $\mathrm{BC} 1+$ bLF and $\mathrm{BC} 2+\mathrm{bLF}$ showed a higher reduction in the bacteria viability, which reached $93.6 \%$ (corresponding to 1-log

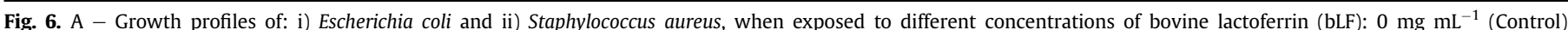



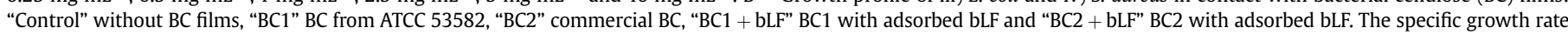

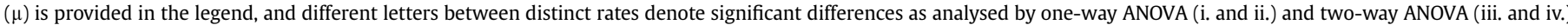

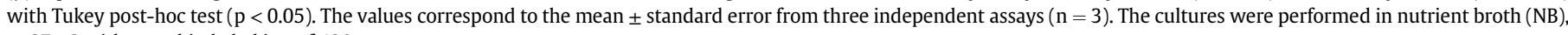
at $37^{\circ} \mathrm{C}$ with an orbital shaking of $120 \mathrm{rpm}$. 
A

i)

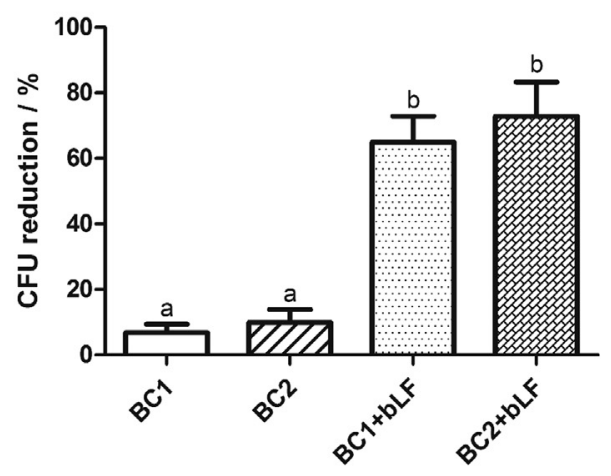

ii)

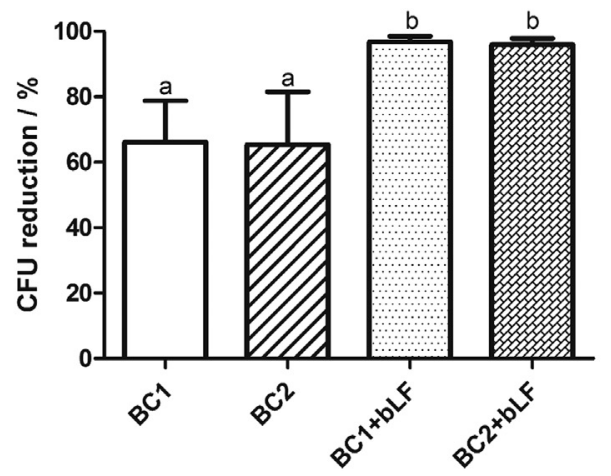

B

iii)

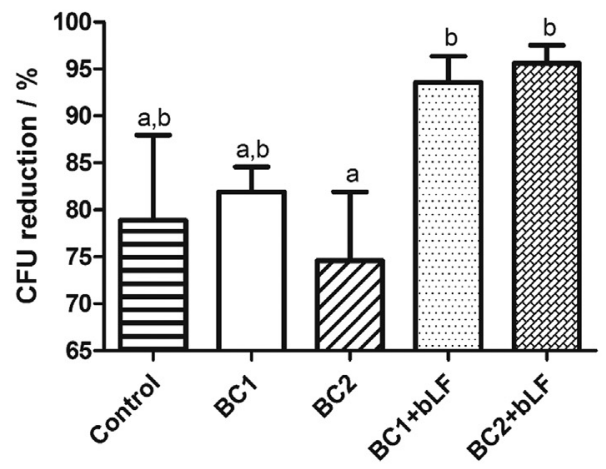

iv)

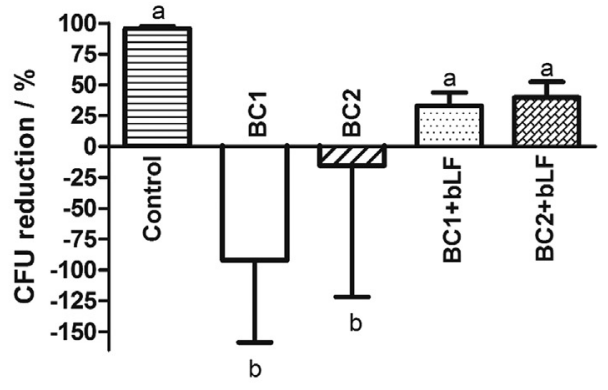

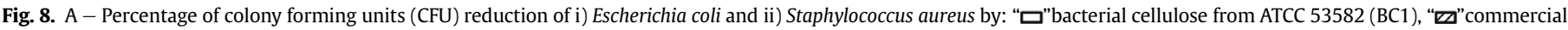

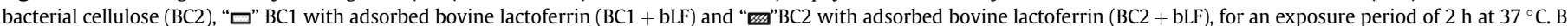

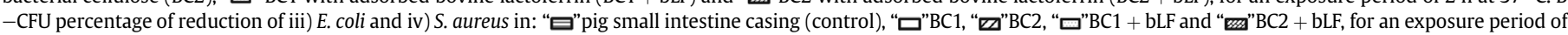

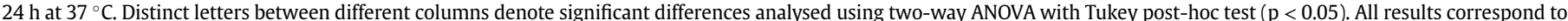
the mean \pm standard error from three independent assays $(n=3)$.

reduction) and $95.9 \%$ (corresponding to 1 -log reduction), respectively. On the other hand, S. aureus actually grew in both BC1 and $\mathrm{BC} 2$, while with pig small intestine, BC1 + bLF and BC2 + bLF inhibition of growth was shown (approximately 52.5\%, 32.9\% and $39.7 \%$, respectively) (Fig. 8B iv). It's noteworthy to mention that, the initial contamination level was indeed high, a condition most likely not encountered in a real case scenario (considering the mass of the fresh sausage used in the assays, the initial microbial load would correspond to $1.2 \times 10^{4} \mathrm{CFU} / \mathrm{g}$ product for $\mathrm{E}$. coli and $1.3 \times 10^{4} \mathrm{CFU} / \mathrm{g}$ product for $S$. aureus; these values would deem the product as "unacceptable" under current European legislation (specifically Council Directives 88/657/EEC (European Parliament, 1988) and 94/ 65/EC (European Parliament, 1994)).

\subsection{Endotoxin level determination}

In Europe, the general principles required by the Regulation (EC) $\mathrm{N}^{\mathrm{o}} 1935 / 2004$ for food contact materials state that these materials must be safe, i.e. they cannot transfer their components into food that could jeopardise the consumer's health, or change in an unacceptable manner or degenerate the food's composition and organoleptic traits. Moreover, the food contact materials (FCM) must be manufactured using good manufacturing practices (European Parliament, 2004, 2006). In the USA, the Food, Drug and Cosmetic Act (Federal Food, 1958) contains the basic regulation on FCM. Briefly, FCM are regulated in the Code of Federal Regulations (CFR.), specifically under Title 21 on Food and Drugs, and Parts 176 to 186 (e-CFR, 2016).

Several toxicological data are necessary to provide information regarding the safety of the food packaging. In this work, an initial assessment on the safety of BC films containing bLF was done. Lipopolysaccharide (LPS) is a characteristic pathogen-associated molecular pattern (PAMP) present in the outer membrane of all Gram-negative bacteria. LPS is widely known for triggering an extremely violent and uncontrolled immune response. Once LPS is recognized in the blood stream, it causes severe cytokine-mediated damage, ultimately leading to death (Akira, Uematsu, \& Takeuchi, 2006; Karima, Matsumoto, Higashi, \& Matsushima, 1999). The BC films herein produced are intended to be used as FCM, thus the absence of LPS must be assured since the BC membranes are produced by a Gram-negative prokaryote. While BC is not absorbed by the intestinal tract, LPS may be released and absorbed, consequently entering the blood stream. The endotoxin values measured on the $\mathrm{BC}$ membranes were $0.851 \pm 0.292$ and $2.027 \pm 0.068 \mathrm{EU} / \mathrm{L}$ for $\mathrm{BC} 1$ and $\mathrm{BC} 2$, respectively. These values are considerably below the maximum threshold of acceptance determined by the Food and Drug Administration (FDA) for general medical devices materials, which is $500 \mathrm{EU} / \mathrm{L}$ (FDA, 1987).

\subsection{Cell viability assessment}

According to the regulatory aspects covered in the previous section, an essential assumption for a film to be considered edible is its absence of cytotoxicity to the human host. Therefore, the new 



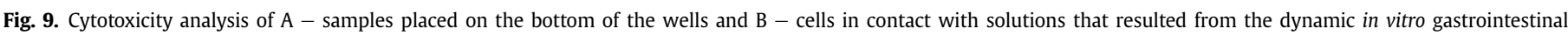

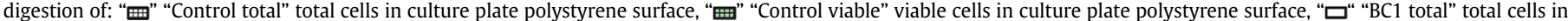

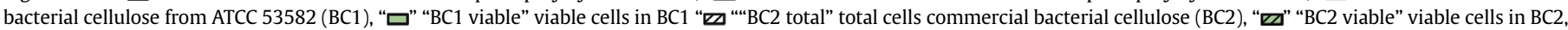

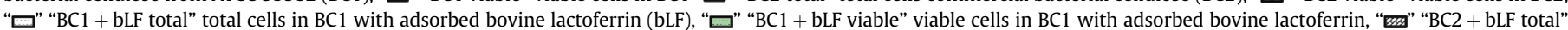



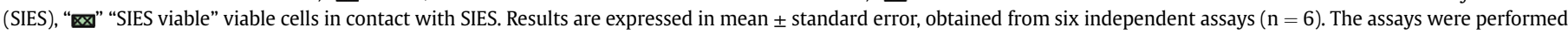
using mammalian mouse embryo fibroblasts $3 \mathrm{~T} 3$ (ATCC CCL-164) at $372 \mathrm{~h}$ of incubation at $37^{\circ}, 5 \% \mathrm{CO}_{2}$ humidified atmosphere.

BC-based materials were evaluated regarding its effect in the 3T3 cell proliferation and viability, both resulting from direct contact and after simulating a dynamic gastrointestinal digestion in a mimetic in vitro dynamic gastrointestinal system. Direct contact with 3T3 cells showed a slight impairment of the cell proliferation after $24 \mathrm{~h}$ of exposure, thus showing low cell adhesion and low proliferation as compared to the control (polystyrene surface). This is in accordance with the results previously reported by our group (Fig. 9A) (F. K. Andrade, Moreira, Domingues, \& Gama, 2010; Pertile, Andrade, Alves Jr, \& Gama, 2010). Among BC films, cell proliferation was identical with similar values of total cells count in films with and without bLF. Cell viability did not suffer any significant impact (Fig. 9A), which is in accordance with other studies reported in the literature. Indeed, no cytotoxicity was expected, since $10 \mathrm{mg} \mathrm{mL}^{-1}$ of bLF has been reported to be non-toxic to CaCO-2 cells (Atef Yekta et al., 2010).

After digestion of the $\mathrm{BC}$ films (with and without bLF) in the mimetic dynamic gastrointestinal system, the 3T3 cells were exposed to the several products resultant from the simulated digestion process (Fig. 9B). The production of an accurate control would imply a gastrointestinal digestion without the ingestion of any produced BC films, which was not feasible. The ileum's main fluid is SIES and it was used as the control sample. Significant differences in the total 3T3 cell counts were only visible after $72 \mathrm{~h}$ of incubation (Fig. 9B). Cell number in BC1 remained identical throughout the experiment, although the minimum percentage of viability was $80 \%$. BC2 + bLF samples presented the highest percentage of viability and demonstrated a significant increase of the cell number after $72 \mathrm{~h}$ of incubation, which may be due to the higher amount of adsorbed bLF. Cells cultured with SIES samples showed similar behaviour to the cells growing with the diluted degradation products; however SIES lacks several of the gastrointestinal components. Overall, the viability was above $70 \%$ in all cases and therefore, non-cytotoxic BC1 + bLF and BC2 + bLF films could have actually promoted cell growth, since bLF has also been reported to act as a growth factor in cell culture (Britton \& Koldovsky, 1989).

\section{Conclusions}

Fully bio-based edible antimicrobial BC films were developed using bLF as the active component. Physicochemical differences were observed between the two different $\mathrm{BC}$, before and after activation with the protein (BC1 + bLF and BC2 + bLF). The WVP of the pig's small intestine casing retrieved from fresh sausages was 5fold higher than the one displayed by the activated $\mathrm{BC}$ films, even though the later possess nearly half of the thickness. The adsorption of bLF caused a shift in the surface properties of the BC films towards their interaction with water, denoting the relevance of the impact of the protein in the $\mathrm{BC}$ films surface properties. Although the mechanical properties of the $\mathrm{BC}$ films were slightly impaired after bLF absorption, the tensile strength remained much higher than that of the pig's small intestine casing.

$\mathrm{BC} 1+\mathrm{bLF}$ and $\mathrm{BC} 2+\mathrm{bLF}$ were able to reduce in vitro the CFU viability of both $E$. coli and $S$. aureus, reaching 1-log reduction in the S. aureus. Contrarily, in the fresh sausage, the bactericidal efficiency was higher for E. coli than for S. aureus. All BC edible films per se and the products resulting from their simulated digestion did not 
exhibit cytotoxicity against fibroblasts. The developed films were found to be bactericidal (even under an unlikely extreme contamination scenario), non-toxic, as well as to have the appropriate technological characteristics to be used as a bio-based meat product casing.

\section{Acknowledgments}

The authors would like to acknowledge Portuguese Foundation for Science and Technology (Fundação para a Ciência e Tecnologia) for the research grants: Jorge Padrão SFRH/BD/64901/2009, Sara Gonçalves SFRH/BD/63578/2009, João Pedro Silva SFRH/BPD/ 64958/2009, Ana Cristina Pinheiro SFRH/BPD/101181/2014. V. Sencadas thanks support from the COST Action MP1206: "Electrospun nano-fibres for bio inspired composite materials and innovative industrial applications" and MP1301: "New Generation Biomimetic and Customized Implants for Bone Engineering". The authors would also like to thank the co-funded by the Programa Operacional Regional do Norte (ON.2 - O Novo Norte), QREN, FEDER Projects "BioHealth - Biotechnology and Bioengineering approaches to improve health quality", Ref. NORTE-07-0124FEDER-000027; "BioInd - Biotechnology and Bioengineering for improved Industrial and Agro-Food processes", REF. NORTE-070124-FEDER-000028; Strategic Project PEST-C/FIS/UI607/2014; Matepro -Optimizing Materials and Processes", ref. NORTE-070124-FEDER-000037; Strategic Project PEst-OE/EQB/LA0023/2013 and project ref. RECI/BBB-EBI/0179/2012 (project number FCOMP01-0124-FEDER-027462). Finally, the authors thank the Fundação para a Ciência e Tecnologia for the strategic funding from the UID/ BIO/04469/2013 unit.

\section{References}

AATCC. (2012). AATCC 100-TM100 antibacterial finishes on textile materials: Assessment of. North Carolina: American Association of Textile Chemists and Colorists.

Aisen, P., \& Leibman, A. (1972). Lactoferrin and transferrin: a comparative study. Biochimica et Biophysica Acta (BBA) - Protein Structure, 257(2), 314-323.

Akira, S., Uematsu, S., \& Takeuchi, O. (2006). Pathogen recognition and innate immunity. Cell, 124(4), 783-801.

Almeida, D. M., Prestes, R. A., Woiciechowski, A. L., \& Wosiacki, G. (2011). Application of bacterial cellulose conservation of minimally processed fruits. Revist Brasileira de Tecnologia Agroindustrial, 5, 356-366.

Andrade, F. K., Moreira, S. M. G., Domingues, L., \& Gama, F. M. P. (2010). Improving the affinity of fibroblasts for bacterial cellulose using carbohydrate-binding modules fused to RGD. Journal of Biomedical Materials Research Part A, 92A(1). $9-17$.

Andrade, F., Pertile, R., Dourado, F., \& Gama, F. (2010). Bacterial cellulose: properties, production and applications. In A. Lejeune, \& T. Deprez (Eds.), Cellulose: Structure and properties, derivatives and industrial uses (pp. 427-458). New York: Nova Science Publishers Inc.

Andrade, F. K., Silva, J. P., Carvalho, M. Castanheira, E. M. S. Soares, R. \& Gama, M. (2011). Studies on the hemocompatibility of bacterial cellulose. Journal of Biomedical Materials Research Part A, 98A(4), 554-566.

ASTM. (1980). Standard test method for water vapor transmission of materials. E96-80 (pp. 771-778). Philadelphia: USA ASTM.

Atef Yekta, M., Verdonck, F., Van Den Broeck, W., Goddeeris, B. M., Cox, E., \& Vanrompay, D. (2010). Lactoferrin inhibits E. coli 0157:H7 growth and attachment to intestinal epithelial cells. Veterinarni Medicina, 55(8), 359-368.

Azeredo, H. M. C. (2013). Antimicrobial nanostructures in food packaging. Trends in Food Science \& Technology, 30(1), 56-69.

Belitz, H.-D., \& Grosch, W. (1999). Food chemistry (2nd ed.). Germany: Springer.

Bellamy, W. Takase, M., Yamauchi, K. Wakabayashi, H., Kawase, K., \& Tomita, M. (1992). Identification of the bactericidal domain of lactoferrin. Biochimica et Biophysica Acta (BBA) - Protein Structure and Molecular Enzymology, 1121(1-2), $130-136$

Bhimani, R. S., Vendrov, Y., \& Furmanski, P. (1999). Influence of lactoferrin feeding and injection against systemic staphylococcal infections in mice. Journal of Applied Microbiology, 86(1), 135-144.

Borch, E., Kant-Muermans, M.-L., \& Blixt, Y. (1996). Bacterial spoilage of meat and cured meat products. International Journal of Food Microbiology, 33(1), 103-120.

Britton, J. R., \& Koldovsky, O. (1989). Gastric luminal digestion of lactoferrin and transferrin by preterm infants. Early Human Development, 19(2), 127-135.

Buser, H. J., Schwarzenbach, D., Petter, W., \& Ludi, A. (1977). The crystal structure of prussian blue: $\mathrm{Fe} 4[\mathrm{Fe}(\mathrm{CN}) 6] 3 . x H 20$. Inorganic Chemistry, 16(11), 2704-2710.

Cagri, A., Ustunol, Z., Osburn, W., \& Ryser, E. T. (2003). Inhibition of Listeria monocytogenes on hot dogs using antimicrobial whey protein-based edible casings. Journal of Food Science, 68(1), 291-299.

Cerqueira, M. A., Costa, M. J., Fuciños, C., Pastrana, L. M., \& Vicente, A. A. (2014), Development of active and nanotechnology-based smart edible packaging systems: physical-chemical characterization. Food and Bioprocess Technology, 7(5), 1472-1482.

Cerqueira, M. A., Souza, B. W. S., Teixeira, J. A., \& Vicente, A. A. (2012). Effect of glycerol and corn oil on physicochemical properties of polysaccharide films - a comparative study. Food Hydrocolloids, 27(1), 175-184.

Chambi, H. N. M., \& Grosso, C. R. F. (2011). Mechanical and water vapor permeability properties of biodegradables films based on methylcellulose, glucomannan, pectin and gelatin. Food Science and Technology (Campinas), 31, 739-746.

Clasen, C. Sultanova, B., Wilhelms, T. Heisig, P. \& Kulicke, W. M. (2006). Effects of different drying processes on the material properties of bacterial cellulose membranes. Macromolecular Symposia, 244(1), 48-58.

Coma, V. (2008). Bioactive packaging technologies for extended shelf life of meatbased products. Meat Science, 78(1-2), 90-103.

Cruz, R. G. (2010). Blend of polymer with polysilsesquioxane barrier; adjust permeability. In: Google Patents.

Cutter, C. N. (2006). Opportunities for bio-based packaging technologies to improve the quality and safety of fresh and further processed muscle foods. Meat Science, 74(1), 131-142.

Dash, S., Murthy, P. N., Nath, L., \& Chowdhury, P. (2010). Kinetic modeling on drug release from controlled drug delivery systems. Acta Poloniae Pharmaceutica Drug Research, 67(3), 217-223.

Duncan, T. V. (2011). Applications of nanotechnology in food packaging and food safety: barrier materials, antimicrobials and sensors. Journal of Colloid and Interface Science, 363(1), 1-24.

e-CFR. (2016). Electronic code of federal regulation. U.S. Government Publishing Office.

EFSA. (2012). Scientific opinion on bovine lactoferrin. In , Vol. 10. EFSA Journal (pp. 1-26). Parma: European Food Safety Authority (EFSA).

European Parliament, C. o. t. E. U.. (1988). Council Directive 88/657/EEC of 14 December 1988 laying down the requirements for the production of and trade in, minced meat, meat in pieces of less than 100 grams and meat preparations and amending Directives 64/433/EEC, 71/118/EEC and 72/462/EEC. Official Journal of the European Union. L 382/3-L 382/14.

European Parliament, C. o. t. E. U.. (1994). Council Directive 94/65/EC of 14 December 1994 laying down the requirements for the production and placing on the market of minced meat and meat preparations. Official Journal of the European Union. L 368/310-L368/331.

European Parliament, C. o. t. E. U.. (2004). Regulation (EC) No 1935/2004 of the European Parliament and of the Council of 27 October 2004 on materials and articles intended to come into contact with food and repealing Directives 80/ 590/EEC and 89/109/EEC. Official Journal of the European Union, 338/334-338/ 317.

European Parliament, C. o. t. E. U.. (2006). Commission Regulation (EC) No 2023 2006 of 22 December 2006 on good manufacturing practice for materials and articles intended to come into contact with food. Official Journal of the European Union. L 384/375-L 384/378.

Fang, Y., Tung, M. A., Britt, I. J., Yada, S., \& Dalgleish, D. G. (2002). Tensile and barrier properties of edible films made from whey proteins. Journal of Food Science, 67(1), 188-193.

FDA. (1987). Guideline on validation of the limulus amebocyte lysate test as an endproduct endotoxin test for human and animal parenteral drugs, biological products and medical devices. In P. H. S (Ed.), Us department of health and human services. Food and Drug Administration.

Federal Food, D, \& Cosmetic Act. (1958). An act to protect the public health by amending the federal food, drug, and cosmetic act to prohibit the use in food of additives which have not bene tested to establish their safety. Public Law, 85-930, 1784-1789.

Gadó, I., Erdei, J., Laszlo, V. G., Pászti, J., Czirók, E., Kontrohr, T., et al. (1991). Correlation between human lactoferrin binding and colicin susceptibility in Escherichia coli. Antimicrobial Agents and Chemotherapy, 35(12), 2538-2543.

Gao, C., Yan, T., Du, J., He, F., Luo, H. \& Wan, Y. (2014). Introduction of broad spectrum antibacterial properties to bacterial cellulose nanofibers via immobilising $\varepsilon$-polylysine nanocoatings. Food Hydrocolloids, 36(0), 204-211.

Gennadios, A., Hanna, M. A., \& Kurth, L. B. (1997). Application of edible coatings on meats, poultry and seafoods: a review. LWT - Food Science and Technology, 30(4), 337-350.

Goncalves, C., Lalatonne, Y., Melro, L., Badino, G., Ferreira, M. F. M., David, L., et al. (2013). New dextrin nanomagnetogels as contrast agents for magnetic resonance imaging. Journal of Materials Chemistry B, 1(42), 5853-5864.

Håkansson, A., Roche, H., Mirza, S., McDaniel, L. S., Brooks-Walter, A., \& Briles, D. E. (2001). Characterization of binding of human lactoferrin to Pneumococcal surface Protein A. Infection and Immunity, 69(5), 3372-3381.

Håversen, L. A., Engberg, I., Baltzer, L., Dolphin, G., Hanson, L.Å., \& Mattsby-Baltzer, I. (2000). Human lactoferrin and peptides derived from a surface-exposed helical region reduce experimental Escherichia coli urinary tract infection in mice. Infection and Immunity, 68(10), 5816-5823.

Henrique, C. M., Teófilo, R. F., Sabino, L., Ferreira, M. M. C., \& Cereda, M. P. (2007). Classification of cassava starch films by physicochemical properties and water vapor permeability quantification by FTIR and PLS. Journal of Food Science, 72(4), E184-E189.

Hestrin, S., \& Schramm, M. (1954). Preparation of freeze-dried cells capable of 
polymerizing glucose to cellulose. Biochemical Journal, 58(2), 345-352.

Irkin, R., \& Esmer, O. K. (2015). Novel food packaging systems with natural antimicrobial agents. Journal of Food Science and Technology.

Karima, R., Matsumoto, S., Higashi, H., \& Matsushima, K. (1999). The molecular pathogenesis of endotoxic shock and organ failure. Molecular Medicine Today, 5(3), 123-132.

Lacroix, M. (2009). Mechanical and permeability properties of edible films and coatings for food and pharmaceutical applications. In K. C. Huber, \& M. E. Embuscado (Eds.), Edible films and coatings for food applications (pp. 347-366). New York: Springer.

Lin, S.-B., Hsu, C.-P., Chen, L.-C., \& Chen, H.-H. (2009). Adding enzymatically modified gelatin to enhance the rehydration abilities and mechanical properties of bacterial cellulose. Food Hydrocolloids, 23(8), 2195-2203.

Maneesri, J., Masniyom, P., \& Pongpiriyadacha, Y. (2012). Bacterial cellulose film containing flavonoids from "Sarapee" (Mammea siamensis) flower extract against Salmonella typhimurium TISTR 292. Journal of Agricultural Science and Technology A, 2, 86-89.

Martins, J. T., Cerqueira, M. A., \& Vicente, A. A. (2012). Influence of $\alpha$-tocopherol on physicochemical properties of chitosan-based films. Food Hydrocolloids, 27(1), 220-227.

Menard, K. P. (2008). Dynamic mechanical analysis: A practical introduction (2nd ed.). Boca Raton: Taylor and Francis Group.

Müller, D., Mandelli, J. S., Marins, J. A., Soares, B. G., Porto, L. M., Rambo, C. R., et al. (2012). Electrically conducting nanocomposites: preparation and properties of polyaniline (PAni)-coated bacterial cellulose nanofibers (BC). Cellulose, 19(5), 1645-1654.

Nazan Turhan, K., \& Sahbaz, F. (2004). Water vapor permeability, tensile properties and solubility of methylcellulose-based edible films. Journal of Food Engineering, 61(3), 459-466.

Nguyen, V. T., Gidley, M. J., \& Dykes, G. A. (2008). Potential of a nisin-containing bacterial cellulose film to inhibit Listeria monocytogenes on processed meats. Food Microbiology, 25(3), 471-478.

Park, H. J., Weller, C. L., Vergano, P. J., \& Testin, R. F. (1993). Permeability and mechanical properties of cellulose-based edible films. Journal of Food Science, 58(6), 1361-1364.

Pereira de Abreu, D. A., Cruz, J. M., \& Paseiro Losada, P. (2011). Active and intelligent packaging for the food industry. Food Reviews International, 28(2), 146-187.

Pérez-Pérez, C., Regalado-González, C., Barbosa-Rodríguez, J. R., RodríguezRodríguez, C. A., \& Villaseñor-Ortega, F. (2006). Incorporation of antimicrobial agents in food packaging films and coatings. In R. G. Guevara-González, \& I. Torres-Pacheco (Eds.), Advances in agricultural and food biotechnology (pp. 193-216). India: Research Signpost.

Pertile, R. A. N., Andrade, F. K., Alves, C., Jr., \& Gama, M. (2010). Surface modification of bacterial cellulose by nitrogen-containing plasma for improved interaction with cells. Carbohydrate Polymers, 82(3), 692-698.

Quintavalla, S., \& Vicini, L. (2002). Antimicrobial food packaging in meat industry. Meat Science, 62(3), 373-380.

Rambo, C. R., Recouvreux, D. O. S., Carminatti, C. A., Pitlovanciv, A. K., Antônio, R. V. \& Porto, L. M. (2008). Template assisted synthesis of porous nanofibrous cellulose membranes for tissue engineering. Materials Science and Engineering: C, 28(4), 549-554.

Realini, C. E., \& Marcos, B. (2014). Active and intelligent packaging systems for a modern society. Meat Science, 98(3), 404-419.

Reis, P. M., Raab, T. W., Chuat, J. Y., Leser, M. E., Miller, R., Watzke, H. J., et al. (2008). Influence of surfactants on lipase fat digestion in a model gastro-intestinal system. Food Biophysics, 3(4), 370-381.

Reller, L. B., Weinstein, M., Jorgensen, J. H., \& Ferraro, M. J. (2009). Antimicrobial susceptibility testing: a review of general principles and contemporary practices. Clinical Infectious Diseases, 49(11), 1749-1755.

Rossi, P., Giansanti, F., Boffi, A., Ajello, M., Valenti, P., Chiancone, E., et al. (2002) $\mathrm{Ca} 2+$ binding to bovine lactoferrin enhances protein stability and influences the release of bacterial lipopolysaccharide. Biochemistry and Cell Biology, 80(1), 41-48.

Sanchez, L., Calvo, M., \& Brock, J. H. (1992). Biological role of lactoferrin. Archives of Disease in Childhood, 67(5), 657-661.

Sangsanoh, P., \& Supaphol, P. (2006). Stability improvement of electrospun chitosan nanofibrous membranes in neutral or weak basic aqueous solutions. Biomacromolecules, 7(10), 2710-2714.

Sani, A., \& Dahman, Y. (2010). Improvements in the production of bacterial synthesized biocellulose nanofibres using different culture methods. Journal of Chemical Technology and Biotechnology, 85(2), 151-164.

Schneider, C. A., Rasband, W. S., \& Eliceiri, K. W. (2012). NIH image to ImageJ: 25 years of image analysis. Nature Methods, 9(7), 671-675.

Sessa, M., Tsao, R., Liu, R., Ferrari, G., \& Donsì, F. (2011). Evaluation of the stability and antioxidant activity of nanoencapsulated resveratrol during in vitro digestion. Journal of Agricultural and Food Chemistry, 59(23), 12352-12360.

Shimazaki, K.-I., Tanaka, T., Kon, H., Oota, K., Kawaguchi, A., Maki, Y., et al. (1993). Separation and characterization of the C-terminal half molecule of bovine lactoferrin. Journal of Dairy Science, 76(4), 946-955.

Shi, Z., Zhang, Y., Phillips, G. O., \& Yang, G. (2014). Utilization of bacterial cellulose in food. Food Hydrocolloids, 35, 539-545.

Siracusa, V., Rocculi, P., Romani, S., \& Rosa, M. D. (2008). Biodegradable polymers for food packaging: a review. Trends in Food Science \& Technology, 19(12), 634-643.

Tafesse, F. (2003). Comparative studies on Prussian Blue or diaquatetraaminecobalt(III) promoted hydrolysis of 4-nitrophenylphosphate in microemulsions. International Journal of Molecular Sciences, 4(6), 362-370.

Tang, W., Jia, S., Jia, Y., \& Yang, H. (2009). The influence of fermentation conditions and post-treatment methods on porosity of bacterial cellulose membrane. World Journal of Microbiology \& Biotechnology, 26(1), 125-131.

Teraguchi, S., Shin, K., Ozawa, K., Nakamura, S., Fukuwatari, Y., Tsuyuki, S., et al (1995). Bacteriostatic effect of orally administered bovine lactoferrin on proliferation of Clostridium species in the gut of mice fed bovine milk. Applied and Environmental Microbiology, 61(2), 501-506.

Verdaguer, M., Galvez, N., Grade, R., \& Desplanches, C. (2002). Electrons at work in prussian blue analogues. The Electrochemical Society Interface, 28-32.

Vorland, L., Ulvatne, H., Andersen, J., Haukland, H., Rekdal, O., Svendsen, J., et al. (1998). Lactoferricin of bovine origin is more active than lactoferricins of human, murine and caprine origin. Scandinavian Journal of Infectious Diseases, 30(5), 513-517.

Wakabayashi, H., Yamauchi, K., \& Takase, M. (2006). Lactoferrin research, technology and applications. International Dairy Journal, 16(11), 1241-1251.

Xavier, P. L., Chaudhari, K., Verma, P. K., Pal, S. K., \& Pradeep, T. (2010). Luminescent quantum clusters of gold in transferrin family protein, lactoferrin exhibiting FRET. Nanoscale, 2(12), 2769-2776.

Yamanaka, S., Watanabe, K., Kitamura, N., Iguchi, M., Mitsuhashi, S., Nishi, Y., et al (1989). The structure and mechanical properties of sheets prepared from bacterial cellulose. Journal of Materials Science, 24(9), 3141-3145.

Zhu, H., Jia, S., Yang, H., Tang, W. Jia, Y. \& Tan, Z. (2010). Characterization of bacteriostatic sausage casing: a composite of bacterial cellulose embedded with ع-polylysine. Food Science and Biotechnology, 19(6), 1479-1484.

Zwietering, M. H., Jongenburger, I., Rombouts, F. M., \& van 't Riet, K. (1990) Modeling of the bacterial growth curve. Applied and Environmental Microbiology, 56(6), 1875-1881. 